Original Research Paper

\title{
Comparison of the Known Hypotheses of Lateral Buckling in the Elastic-Plastic States of Thin-Walled Semi-Slender Columns
}

\author{
Krzysztof Murawski \\ Independent Researcher, Poland
}

Article history

Received: 02-10-2020

Revised: $10-12-2020$

Accepted: 21-12-2020

Email: saeid.elkatlawy@gmail.com

\begin{abstract}
Stability of structures, as known, is a challenging issue, especially in critical engineering, i.e., in designing structures which in a wrong design process could cause a catastrophe. The avoidance of possible stability troubles is mandatory. In this study, the simplifications and hypotheses of loss of stability by lateral buckling in elastic-plastic states of semi-slender columns axially compressed by force are presented. The Tetmajer-Jasiński's and Johnson-Ostenfeld's simplifications as well as Engesser-Kármán-Shanley's, Ylinen, Březina, Pearson-Bleich-Vol'mir's and author's approximated hypotheses are analysed. The graphs of surface functions of the compressing critical stress $\sigma_{c r}$ depending on the ratios $\mu=$ $a / t$ or $\delta=R / t$ and $\chi=L / t$ are presented as the theoretical examples of thinwalled cylindrical and square columns made of steel R35. In order to compare the results of the author's approximated hypothesis, i.e., the modified Engesser-Kármán-Shanley's hypothesis with others simplifications and hypotheses are shown in adequately ranges for elasticplastic states as the graphs of the functions $\sigma_{c r}(\lambda)$.
\end{abstract}

Keywords: Stability, Buckling, Elastic-Plastic States, Semi-Slender, Column

\section{Introduction}

Shell structures, in the field of building construction and engineering in general, represent a thin, curved plate structure that is optimally shaped to transmit applied forces by compressive, tensile and shear stresses that act in the plane of the same surface. When we consider the application of shell elements in load-bearing structures, accordingly, the first issue to analyze is their load capacity to sustain axial loads, i.e., their stability and susceptibility to potential buckling collapse mechanisms that could compromise the structure and occupant safety. In the case of very slender columns, this refers to the problem of stability in elastic states.

The basic theory of slender rods losing stability in elastic states, as known, has been originally formulated by (Euler, 1744; 1759). He first introduced the concept of critical load $P_{c r}$ and presented, according to his theory, the differential equation of an elastic deflected central line.

The stability phenomenon of semi slender columns in elastic-plastic states was researched too, by (Tetmajer, 1886; Jasiński, 1894; Engesser, 1889; 1895; Ostenfeld,
1898; von Kármán, 1908; Kármán, 1910; Shanley, 1947; Stowell, 1948; Bijlaard, 1949; Bleich, 1952; Broszko, 1953; Ylinen, 1956; Radhakrishnan, 1956; Gerard and Becker, 1957; Gerard, 1957; 1962; Seide et al., 1960; Vol'mir, 1965; Březina, 1966).

This phenomenon was later researched by others.

Brank et al. (1997) presented a large-deformation model for thin shells composed of elastic-plastic material. Formulation of the shell model, equivalent to the two-dimensional Cosserat continuum, was developed from the three-dimensional continuum by employing standard assumptions on the distribution of the displacement field in the shell body. A model for thin shells was obtained by an approximation of terms describing the shell geometry. Finite rotations of the director field were described by a rotation vector formulation. An elastic-plastic constitutive model was developed based on the von Mises yield criterion and isotropic hardening.

Lepik (1999) considered a bifurcation of axially loaded elastic-plastic cylindrical shells in the case of axisymmetric buckling. The effect of stress waves travelling along the shell was taken into account. It was 
assumed that the shell material had linear strain hardening. The analysis was carried out for both the deformation and for the flow theory of plasticity. For solving the problem the quasi-bifurcation method was applied. Buckling threshold and spectrum of bifurcation times were calculated. A coefficient characterizing exponential growth of the buckling amplitudes was introduced. The numerical examples were presented.

Papanastasiou and Durban (1999) presented a linear bifurcation analysis for pressure sensitive elastoplastic hollow cylinders under radial surface loads. Material response was modeled by the flow and deformation theories of the Drucker-Prager solid accounting for arbitrary hardening. Sample calculations were given for cylinders that deformed in axially symmetric patterns under uniform radial pressure applied at the boundaries. For thick-walled cylinders the dominant bifurcation mode predicted by deformation theory appeared to be a circumferential surface instability. Deformation theory results for bifurcations were apparently not sensitive to deviations from associativity.

Dubina and Ungureanu (2000) dealt with the elasticplastic interactive buckling of thin-walled steel compression members. The interaction formula for local and overall buckling modes of Thin-Walled Steel Compression (TWSC) members, the effect of local buckling was introduced by means of the effective strength of short members. The local overall interactive buckling modes were regarded as interaction between local rigid-plastic mode and overall-elastic one and these two modes were coupled into an adequate interactive equation.

Alvarenga and Silveira (2006) presented a study about the necessary steps to qualify a second-order inelastic analysis as advanced one. A plastic-zone approach applied to steel plane frames (portals) and the numerical formulation was based on finite element model of a Bernoulli-Euler beam-column member called "slice technique". This element was set on a Lagrangian updated co-rotational system. The nonlinear problem was solved using Newton-Raphson iterative strategy and a new axial force iterative integration was shown. This process was implemented on a computer program PPLANAV* and the minimum requirements of advanced analysis (initial geometrical imperfections and residual stress) were automatically generated.

Fraldi et al. (2008) aimed at deriving assessment and design formulae for determining the elastic-plastic response and the ultimate compressive strength of circular concrete columns confined by Fiber Reinforced Polymers (FRP). A constructive method for obtaining closed-form elastic and post-elastic solutions for Functionally Graded Material Cylinders (FGMCs), constituted by an isotropic central core and arbitrary cylindrically orthotropic hollow phases, was proposed.
The hypotheses of axis-symmetrical boundary conditions, elasticity and perfect bond between the phases, with a new analytical solutions for self-equilibrated axial forces applied were derived. The elastic and post-elastic response of the overall solid and predictive formulae for estimating the failure mechanism, in terms of concrete ultimate compressive strength, confining pressure and strain at failure, were derived.

Voyiadjis and Woelke (2008) presented a finite element model for the elastic-plastic and damage analysis of thin and thick shells. Linear elastic, inelastic and softening behaviors caused by damage in structural shells, as well as large rotations were investigated. The presented formulation was developed primarily for large scale structural analyses. They provided a constitutive model which allowed for accurate representation of the non-linear shell behavior up to failure, while offering high efficiency and applicability to large scale structural analyses. This was achieved by representing the elasticplastic behavior by means of the non-layered approach, with an updated Lagrangian method used to describe the geometric non-linearities. For the treatment of material non-linearities an Iliushin's yield function expressed in terms of stress resultants was adopted, with isotropic and kinematic hardening rules.

Leoveanu et al. (2012) searched the steel light structures used in tall buildings, bridges piles and girders. They realize a smallest loading by the own weight of the structure components by designing in elastic-plastic state so the global and local instability was important. They designed buildings with using the welding joint technology. The authors tried to simplify the calculation process by use some statistical low to approximate some of the complex phenomenon and get good estimations on the residual stresses induced by the welded process in the double $T$ profile. The verification of the influence of technology on the girder instability was easy to estimate the critical loads.

Al-Kamal (2017) analysed the elastic stability of a column bolted at its mid-height to a simply supported square plate and subjected to a concentrated load, using the energy method. A uniform, homogeneous column was assumed to be pinned at both ends. From symmetry considerations, half of the column was modeled by making the plate acting as a torsion spring on the column at its mid-height. The analytical elastic buckling load was compared with a numerical solution obtained from finite element method using SAP2000.

Silvestre et al. (2018) studied the influence of the nature of the deformation mode (global, local and distortional) on the load carrying capacity of beams beyond the yield load. Following recent investigations on the decomposition of elastic buckling modes into combinations of structurally meaningful deformation modes, they applied the same concept to the 1 st order 
failure modes (elastic-plastic collapse mechanisms). To achieve this goal, a GBT-based code that performed firstorder elastic-plastic analyses of thin-walled members was employed. The five beams with different cross-sections, lengths, supports and loadings were analysed. It was concluded that larger contributions of local and distortional modes of the beam failure mode lead to a higher post-yielding strength reserve, which implied a higher beam load carrying capacity beyond the yield load.

Słowiński and Piekarczyk (2017) dealt with a safe and economic design of steel cylindrical shells according to European Standard EN 1993-1-6 often requiring a non-linear analysis. The plastic collapse load resulting from a materially non-linear analysis was to be determined then in many cases. However, an extraction of the true plastic strength still was a relatively complex matter in a numerical analysis. The authors used the modified Southwell plot and also the plot between the load factor increment and the arc length for an evaluation of the plastic collapse resistance of a steel cylindrical shell. A proposal of an employment of the relation between the load factor increment and the arc length, which permitted to track the structural response of the whole shell during the progress of the numerical computations, was made.

Krishan et al. (2019) presented a theoretical study of the structural resistance of compressed short concrete elements in a glass-fiber reinforced shell. The methodology was based on a nonlinear strain model of how this element reacts to incremental load in. What made computing of such structures difficult was the need to account for the continuously changing lateral shell pressure on the concrete core. The lateral pressure kept increasing due to changes in the concrete-core and glass fiber-reinforced shell lateral-strain coefficients, causing greater stress in the material.

\section{Stability of Semi-Slender Columns in Elastic- Plastic States}

An application of thin-walled columns for structures mainly depends on their load capacity for axial loads, i.e., their stability. In the case of very slender columns, this will refer to the stability in elastic states, but more often in engineering practice in the elastic-plastic states.

In an analysis of stability in practical designing for squat columns the determining of critical force may be used by a simplification formulated by (Tetmajer, 1886; Jasiński, 1894), which relies on replacement the Euler's hyperbole by the Tetmajer-Jasiński's straight line.

For materials having the limit of the plastic stress $\sigma_{p l}(\lambda=0)=R_{e}{ }^{*} \approx R_{e}$ (Fig. 16), where $R_{e}$ is the yield stress and the limit of the elastic stress $\sigma_{H}\left(\lambda=\lambda_{\text {el_lt }}\right)=R_{H}^{E u}$ (Fig. 16) the co-ordinates of Tetmajer-Jasiński's straight line:

$$
\sigma_{c r}=\sigma_{H}=R_{H}^{E u} \text { for } \lambda=\lambda_{\text {el_lt }}
$$

(simultaneously on the Euler's hyperbole) and:

$\sigma_{c r}=\sigma_{p l}=R_{e}^{*}$ for $\lambda=0$.

where, $\lambda$ denotes the slenderness ratio.

In that case the formula of Tetmajer-Jasiński's straight line is as follows:

$\sigma_{c r}^{T-J}=R_{e}^{*}-\frac{R_{e}^{*}-R_{H}^{E u}}{\lambda_{e l_{-} l t}} \cdot \lambda$.

For semi-slender thin-walled cylindrical columns depending on $\delta$ and $\chi$ the critical stresses are (Fig. 1) as follows:

$\sigma_{c r_{-} c y l i n d r}^{T-J}=R_{r}^{*}-\sqrt{2} \cdot \frac{\left(R_{e}^{*}-R_{H}^{E u}\right) \cdot \chi}{\lambda_{e l_{-} l t} \cdot \delta}$,

where, $\delta=R / t$ and $\chi=L / t$, while:

$R \quad$ Denotes the median radius of the cylinder,

$L \quad$ The length of the column,

$t \quad$ The wall thickness and

$\lambda_{\text {el_lt }}$ The slenderness ratio limiting the elasticstate.

For semi-slender thin-walled square columns depending on $\mu$ and $\chi$ critical stresses are (Fig. 2):

$\sigma_{c r_{-} \text {square }}^{T-J}=R_{e}^{*}-\sqrt{6} \cdot \frac{\left(R_{e}^{*}-R_{H}^{E u}\right) \cdot \chi}{\lambda_{e l_{-} l t} \cdot \mu}$,

where, $\mu=a / t$ and $\chi=L / t$, while: $a$ is denotes the median side of the square.

The Tetmajer-Jasiński's simplification was described in the paper (Murawski, 2008d).

The next simplification which may be used in analysis of stability for squat columns to the determining of critical force in practical designing is the one formulated by (Ostenfeld, 1898).

The simplification relies on replacement the Euler's hyperbole by the Johnson-Ostenfeld's parabola.

For materials having the limit of plastic stress $\sigma_{p l}=R_{e}{ }^{*}$ :

$\sigma_{c r}=\sigma_{p l}=R_{e}^{*}$ for $\lambda=0$.

The formula of Johnson-Ostenfeld's parabola is as follows:

$\sigma_{c r}^{J-O}=R_{e}^{*}-\frac{R_{e}^{* 2}}{4 \cdot E \cdot \pi^{2}} \cdot(\lambda)^{2}$,

where, $E$ denotes the Young's elastic modulus. 


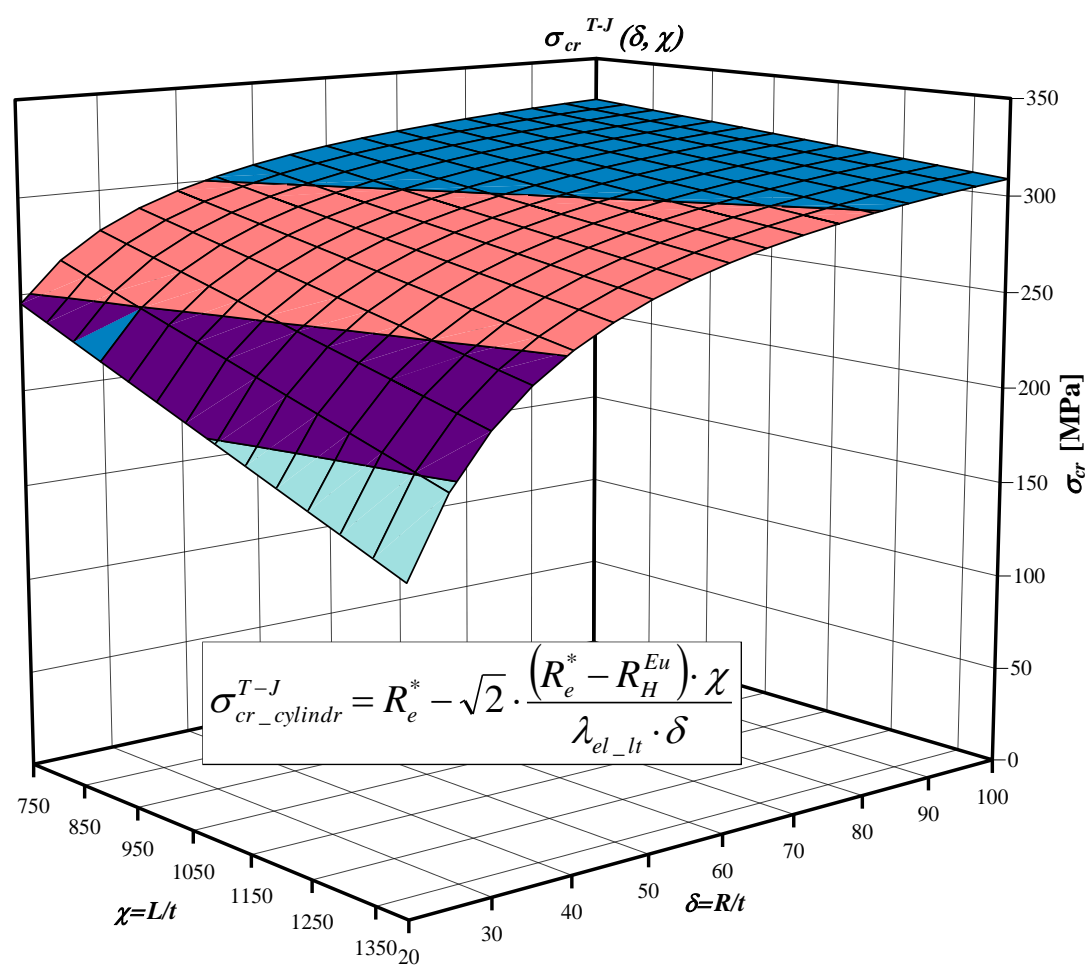

Fig. 1: Surface function $\sigma^{T-J}{ }_{c r}$ cylindr $(\delta, \chi)$ based on the Tetmajer-Jasiński formula of the cylindrically-shaped columns made of steel R35 compressed by ball-and-socket joints.

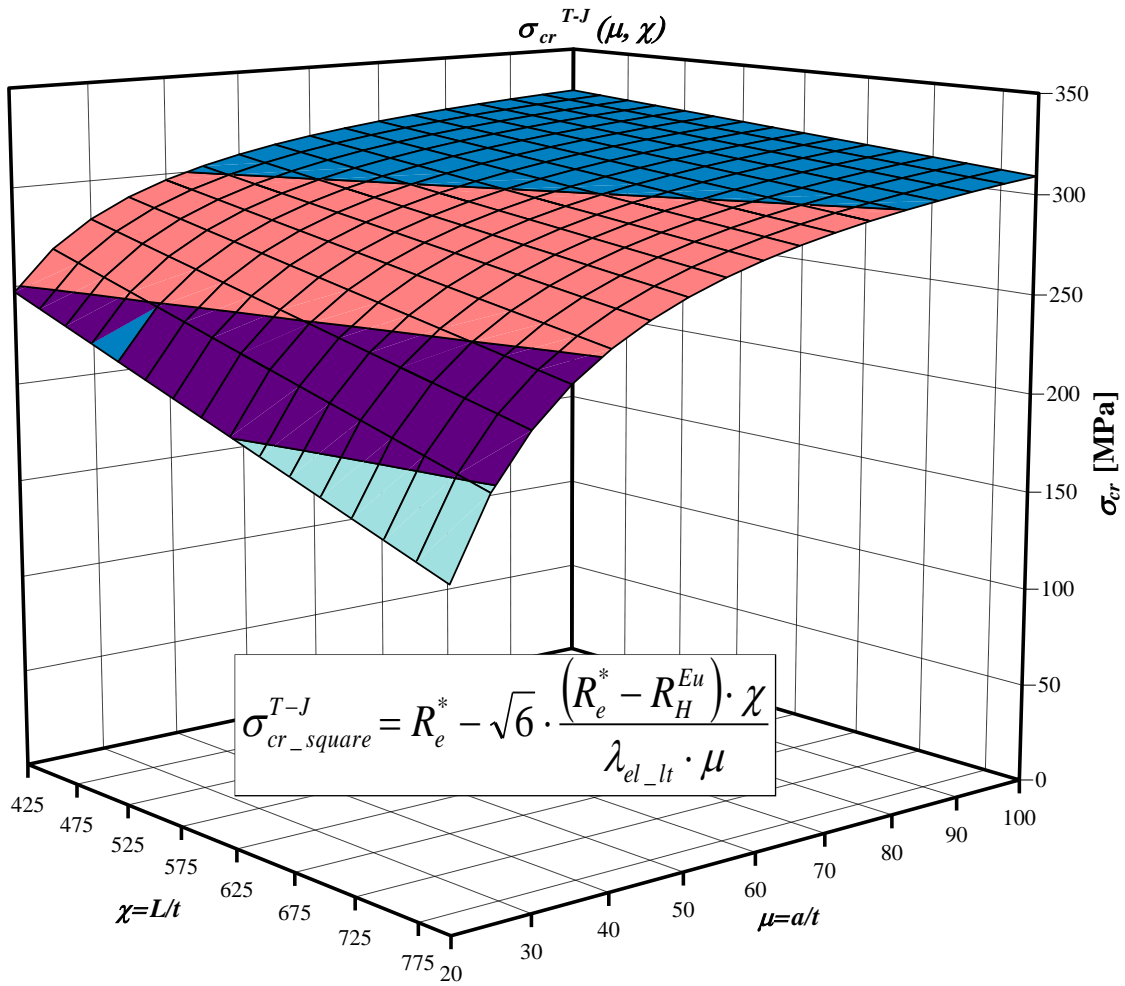

Fig. 2: Surface function $\sigma^{T-J}$ cr_square $_{-}(\mu, \chi)$ based on the Tetmajer-Jasiński formula of the square-shaped columns made of steel R35 compressed by ball-and-socket joints 


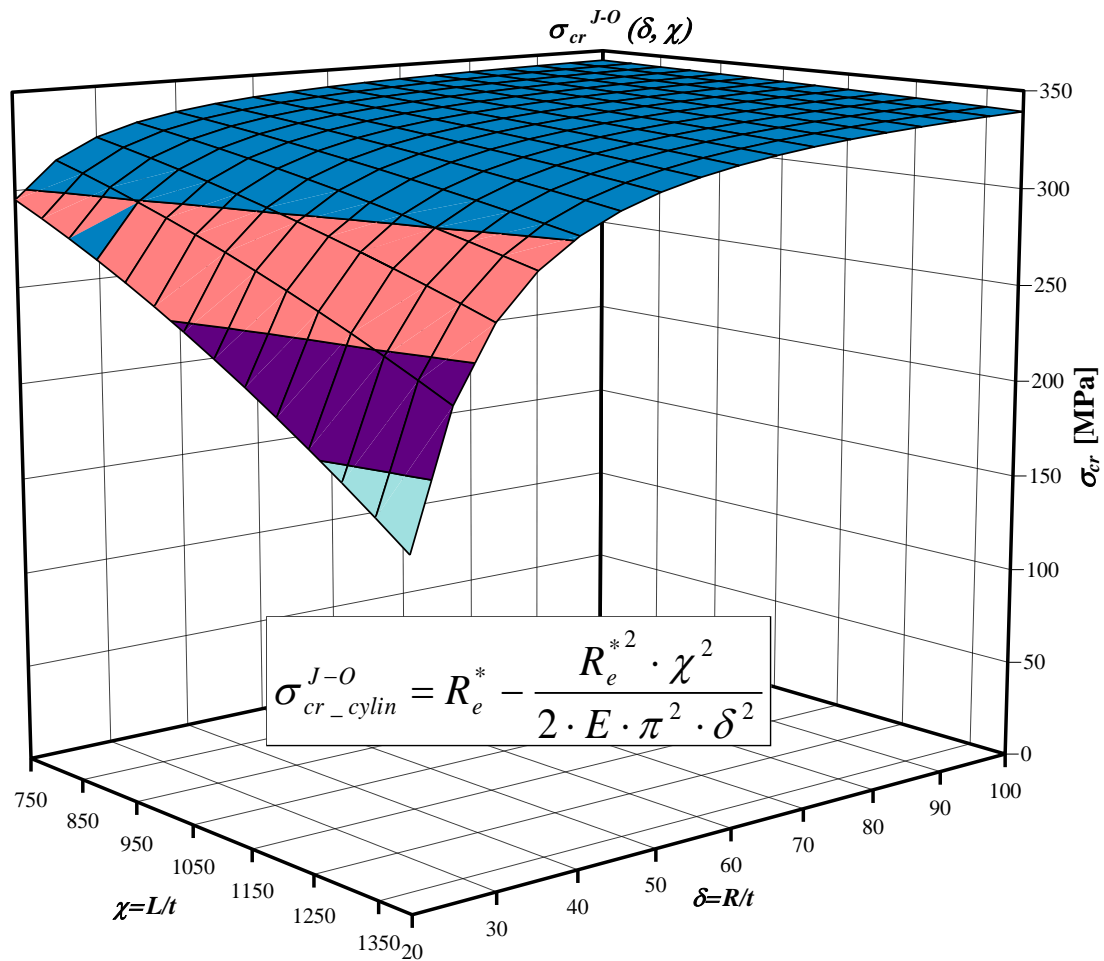

Fig. 3: Surface function $\sigma^{J-O}{ }_{c r}$ cylindr $(\delta, \chi)$ based on the Johnson-Ostenfeld formula of the cylindrically-shaped columns made of steel R35 compressed by ball-and-socket joints

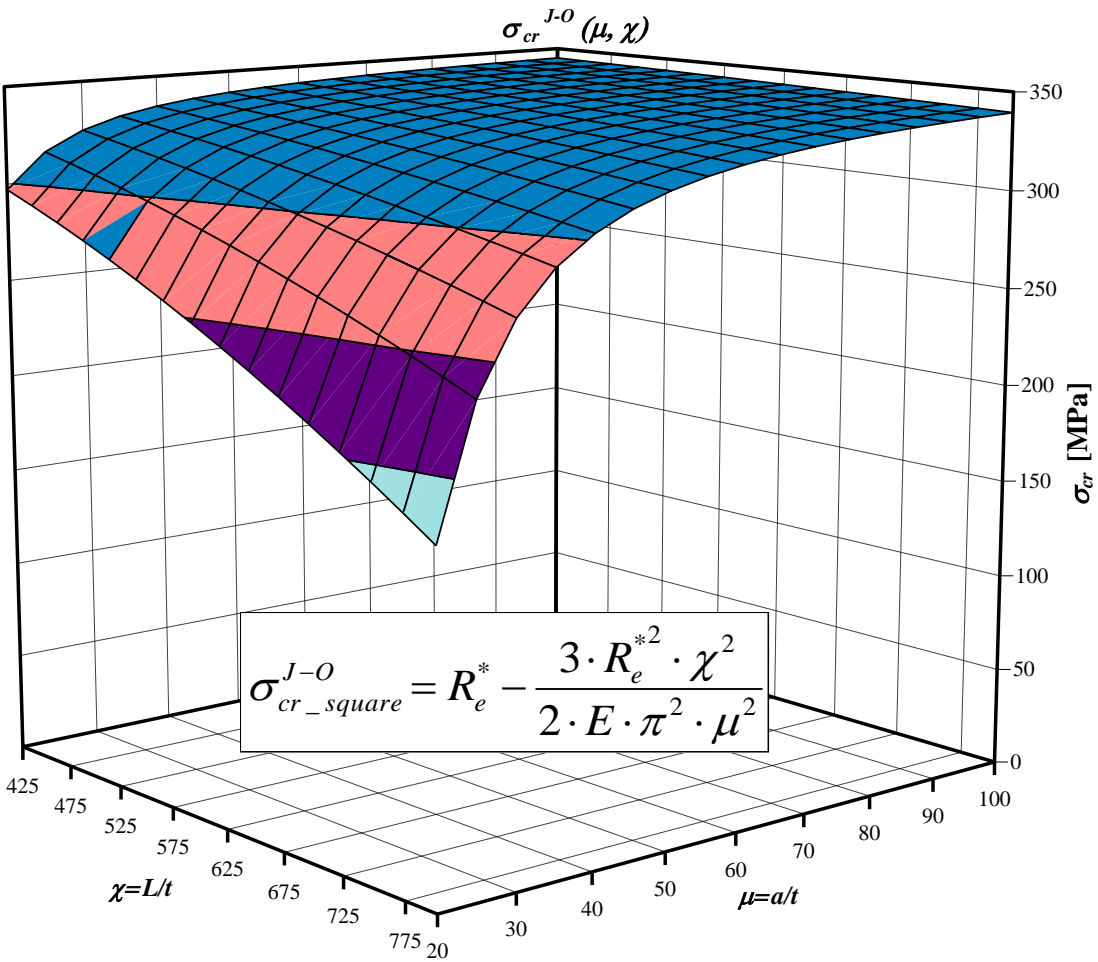

Fig. 4: Surface function $\sigma^{J-O} r_{-}$square $(\mu, \chi)$ based on the Johnson-Ostenfeld formula of the square-shaped columns made of steel R35 compressed by ball-and-socket joints 
For semi-slender thin-walled cylindrical columns depending on $\delta$ and $\chi$ critical stresses are (Fig. 3):

$\sigma_{c r_{-} \text {cylind }}^{J-O}=R_{e}^{*}-\frac{R_{e}^{* 2}}{4 \cdot E \cdot \pi^{2}} \cdot\left(\sqrt{2} \frac{\chi}{\delta}\right)^{2}$,

For semi-slender thin-walled square columns depending on $\delta$ and $\chi$ critical stresses are (Fig. 4):

$\sigma_{\text {cr_s square }}^{J-O}=R_{e}^{*}-\frac{R_{e}^{* 2}}{4 \cdot E \cdot \pi^{2}} \cdot\left(\sqrt{6} \frac{\chi}{\mu}\right)^{2}$.

The Johnson-Ostenfeld's simplification was described in the paper (Murawski, 2008e).

The loss stability theory of axially compressed semislender columns in elastic-plastic states, based on the concept of the tangent modulus, was formulated by (Engesser, 1889; 1895; von Kármán, 1908; Kármán, 1910; Shanley, 1947). According to the EngesserKármán-Shanley's hypothesis, the following two zones can be found in the critical cross-section of the axially compressed column in elastic-plastic state:

- The squeezed zone, deformed plastically on the concave side of the neutral layer of the column and

- The tensioned zone, deformed elastically on the convex side - Fig. 5 a

It was assumed, from the equilibrium of forces and moments in relation to the elastic line of the column before the loss of stability that the sum of forces due to the stresses as well as the sum of moments has to be equal to zero - Fig. 5 b.

In addition, the elastic zone was characterized with Young's modulus $E$ and the plastic zone - with the socalled tangent modulus $E_{t}$, determined like Young's modulus from the graph stress $\sigma$-strain $\varepsilon$, obtained during a standard tension test, but from the non-linear range.

The Engesser-Kármán-Shanley's theory was described in the papers and books (Murawski, 1998; 2002a; 2002b; 2003; 2008a; 2011a; 2011b; 2011c; 2017; 2018).

The formula for the Engesser-Kármán's critical stress is like Euler's but instead of the Young's elastic modulus $E$ was used Engesser-Kármán's modulus $E_{E K}$ :

$$
\sigma_{c r}^{\text {Engesser-Karman }}=\left(\frac{\pi}{\lambda}\right)^{2} E_{E K} .
$$

Shanley took advantage of this formula, replacing $E_{E K}$ directly by tangent modulus $E_{t}$ :

$$
\sigma_{c r}^{\text {Engesser-Shanaly }}=\left(\frac{\pi}{\lambda}\right)^{2} E_{t} .
$$

But this formula does not give satisfactorily correct results, too.
The determination of the course of the function $E_{t}(\lambda)$ on the basis of this formula knowing the $\sigma_{c r}(\lambda)$ function from experiments allows receiving the correct results in range of a population of examined specimens only.

Later (Ylinen, 1956) used the approximation of the function $E_{t}=d \sigma / d \varepsilon=E_{t}(\sigma)$ with the equation:

$$
E_{t}=E\left(\frac{R_{e}-\sigma_{c r}}{R_{e}-c \cdot \sigma_{c r}}\right),
$$

Where:

$R_{e}=$ The yield stress and

$c=$ Denotes dimensionless constant determined by experiment ( $c=0.977$ for steel, $c=0.875$ for wood, $c=0$ for concrete)

The physical meaning of quadratic equation with respect to $\sigma_{c r}$ :

$$
\sigma_{c r}^{\text {Ylien }}=\left(\frac{\pi}{\lambda}\right)^{2} E\left(\frac{R_{e}-\sigma_{c r}^{\text {Ylien }}}{R_{e}-c \cdot \sigma_{c r}^{\text {Ylien }}}\right)
$$

has its root:

$$
\sigma_{c r}^{\text {Ylinen }}=\frac{2 \cdot R_{e}}{1+\left(\frac{\lambda}{\pi}\right)^{2} \frac{R_{e}}{E}+\sqrt{\left(1+\left(\frac{\lambda}{\pi}\right)^{2} \frac{R_{e}}{E}\right)^{2}-4 \cdot c \cdot\left(\frac{\lambda}{\pi}\right)^{2} \frac{R_{e}}{E}}}
$$

For the semi-slender thin-walled cylindrical column axially compressed by ball-and-socket joints the critical stress, according to Ylinen (Fig. 6) equals:

$$
\begin{aligned}
& \sigma_{c r_{-} \text {ylindr }}^{\text {Ylinen }}=\frac{2 . R_{e}}{1+\left(\frac{\sqrt{2} \cdot \chi}{\pi \cdot \delta}\right)^{2} \frac{R_{e}}{E}+\sqrt{\left(1+\left(\frac{\sqrt{2} \cdot \chi}{\pi \cdot \delta}\right)^{2} \frac{R_{e}}{E}\right)^{2}-4 \cdot c \cdot\left(\frac{\sqrt{2} \cdot \chi}{\pi \cdot \delta}\right)^{2} \frac{R_{e}}{E}}} \\
& \sigma_{\text {cr }_{-} \text {square }}^{\text {Ylien }}=\frac{2 \cdot R_{e}}{1+\left(\frac{\sqrt{6} \cdot \chi}{\pi \cdot \mu}\right)^{2} \frac{R_{e}}{E}+\sqrt{\left(1+\left(\frac{\sqrt{6} \cdot \chi}{\pi \cdot \mu}\right)^{2} \frac{R_{e}}{E}\right)^{2}-4 \cdot c \cdot\left(\frac{\sqrt{6} \cdot \chi}{\pi \cdot \mu}\right)^{2} \frac{R_{e}}{E}}}
\end{aligned}
$$

The Ylinen's theory was described in the paper (Murawski, 2008b).

Březina (1966) used the function $\sigma(\varepsilon)$ according to the (Standard DIN 4114, 1953):

$$
E_{t}^{D I N 4114}=E \cdot\left[1-\left(\frac{\sigma-R_{x}}{R_{e}-R_{x}}\right)^{2}\right],
$$

Where:

$R_{x}=$ The limit of proportional stress

$R_{e}=$ Denotes the yield stress 
and then the Engesser-Shanlay's formula was changed to the form:

$\sigma_{c r}^{\text {Brzezina }}=\left(\frac{\pi}{\lambda}\right) \cdot E \cdot\left[1-\left(\frac{\sigma_{c r}^{\text {Brezina }}-R_{x}}{R_{e}-R_{x}}\right)^{2}\right]$.

The root of this quadratic equation with respect to $\sigma_{c r}$ would be as follows:

$$
\begin{aligned}
& \sigma_{c r}^{\text {Brzezina }}=\frac{1}{2}\left\{\left[2 R_{x}-\frac{\left(R_{e}-R_{x}\right)^{2}}{E \cdot\left(\frac{\pi}{\lambda}\right)^{2}}\right]\right. \\
& +\sqrt{\left.\left[2 R_{x}-\frac{\left(R_{e}-R_{x}\right)^{2}}{E \cdot\left(\frac{\pi}{\lambda}\right)^{2}}\right]^{2}-4 \cdot\left[R_{x}^{2}-\left(R_{e}-R_{x}\right)^{2}\right]\right\}}
\end{aligned}
$$

For the semi-slender thin-walled cylindrical column axially compressed by ball-and-socket joints the critical stress, according to Březina is equal to (Fig. 8):

$$
\begin{aligned}
& \sigma_{c r_{-} \text {Bylindr }}^{\text {Brezina }}=\frac{1}{2}\left\{\left[2 R_{x}-\frac{\left(R_{e}-R_{x}\right)^{2}}{E \cdot}\left(\frac{\sqrt{2} \cdot \chi}{\pi \cdot \delta}\right)^{2}\right]\right. \\
& +\sqrt{\left.\left[2 R_{x}-\frac{\left(R_{e}-R_{x}\right)^{2}}{E \cdot}\left(\frac{\sqrt{2} \cdot \chi}{\pi \cdot \delta}\right)^{2}\right]^{2}-4 \cdot\left[R_{x}^{2}-\left(R_{e}-R_{x}\right)^{2}\right]\right\}} .
\end{aligned}
$$

For the semi-slender thin-walled square column axially compressed by ball-and-socket joints the critical stress, according to Březina is equal to (Fig. 9):

$$
\begin{aligned}
& \sigma_{\text {cr } r_{-} \text {square }}^{\text {Brezina }}=\frac{1}{2}\left\{\left[2 R_{x}-\frac{\left(R_{e}-R_{x}\right)^{2}}{E \cdot}\left(\frac{\sqrt{6} \cdot \chi}{\pi \cdot \delta}\right)^{2}\right]\right. \\
& +\sqrt{\left.\left[2 R_{x}-\frac{\left(R_{e}-R_{x}\right)^{2}}{E \cdot}\left(\frac{\sqrt{6} \cdot \chi}{\pi \cdot \delta}\right)^{2}\right]^{2}-4 \cdot\left[R_{x}^{2}-\left(R_{e}-R_{x}\right)^{2}\right]\right\}} .
\end{aligned}
$$

The Březina's hypothesis was described in the paper (Murawski, 2008c).

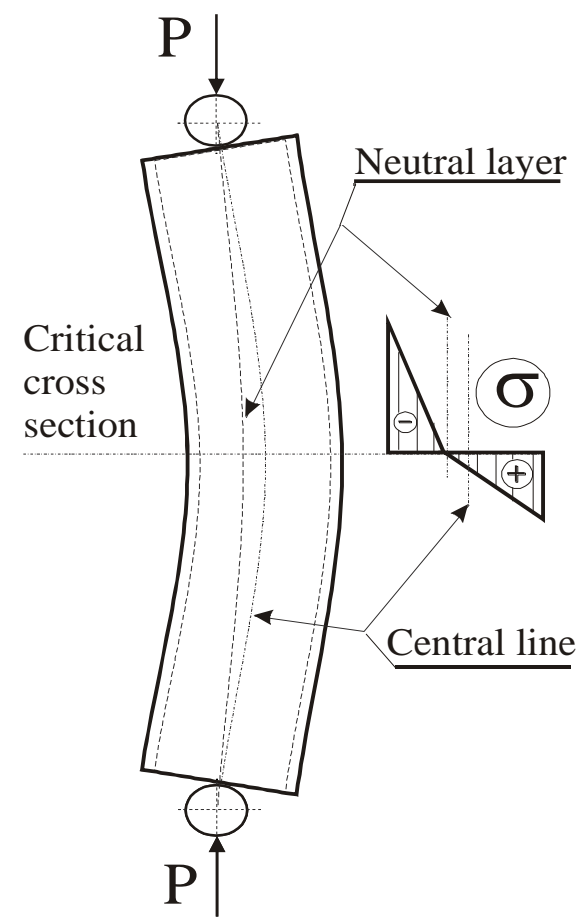

(a)

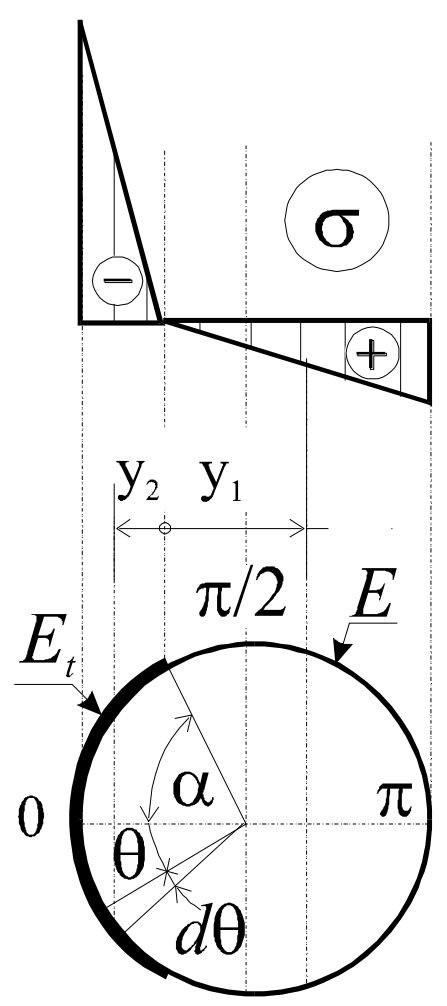

(b)

Fig. 5: Axially compressed column (a) and its critical cross-section (b) at the moment of the stability loss, according to the EngesserKármán-Shanley's hypothesis; the Young's modulus $E$, and tangent modulus $E_{t}$ during tension 


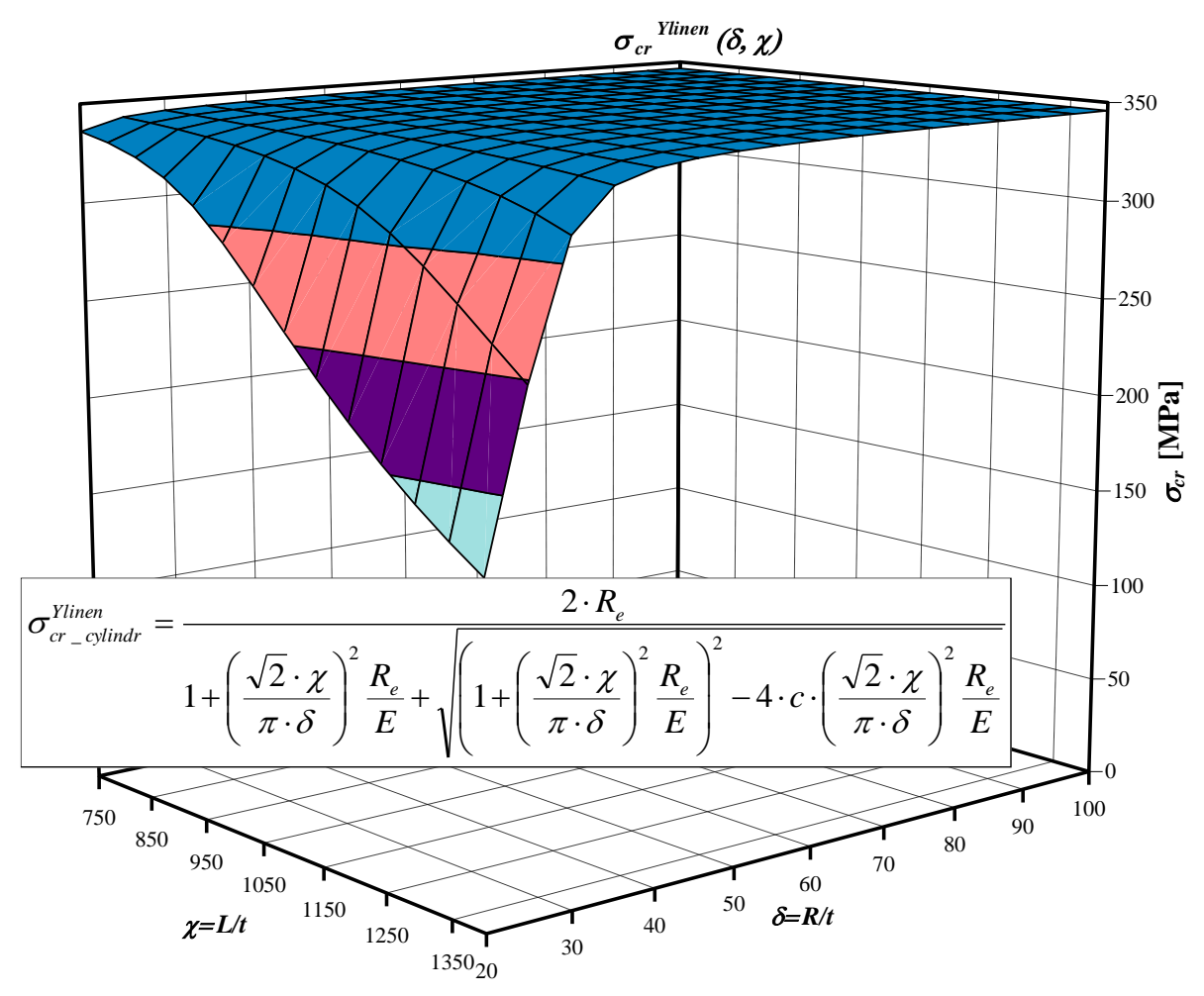

Fig. 6: Surface function $\sigma^{\text {Ylinen }}{ }_{{ }_{1}-c y l i n d r}(\delta, \chi)$ based on the Ylinen's formula of the cylindrically-shaped columns made of steel R35 compressed by ball-and-socket joints

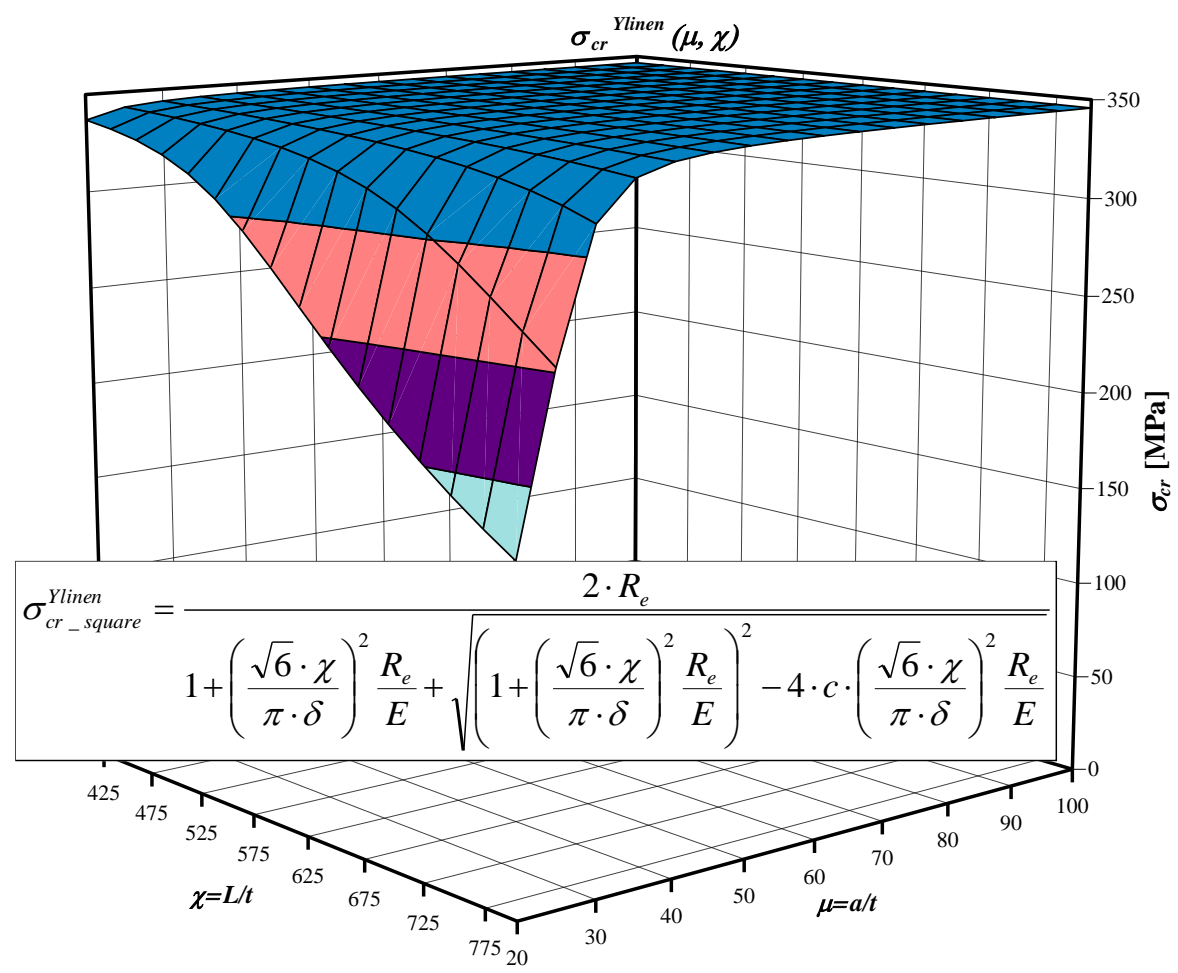

Fig. 7: Surface function $\sigma^{\text {Ylinen }}{ }_{\text {cr_square }}(\mu, \chi)$ based on the Ylinen's formula of the square-shaped columns made of birch compressed by ball-and-socket joints 


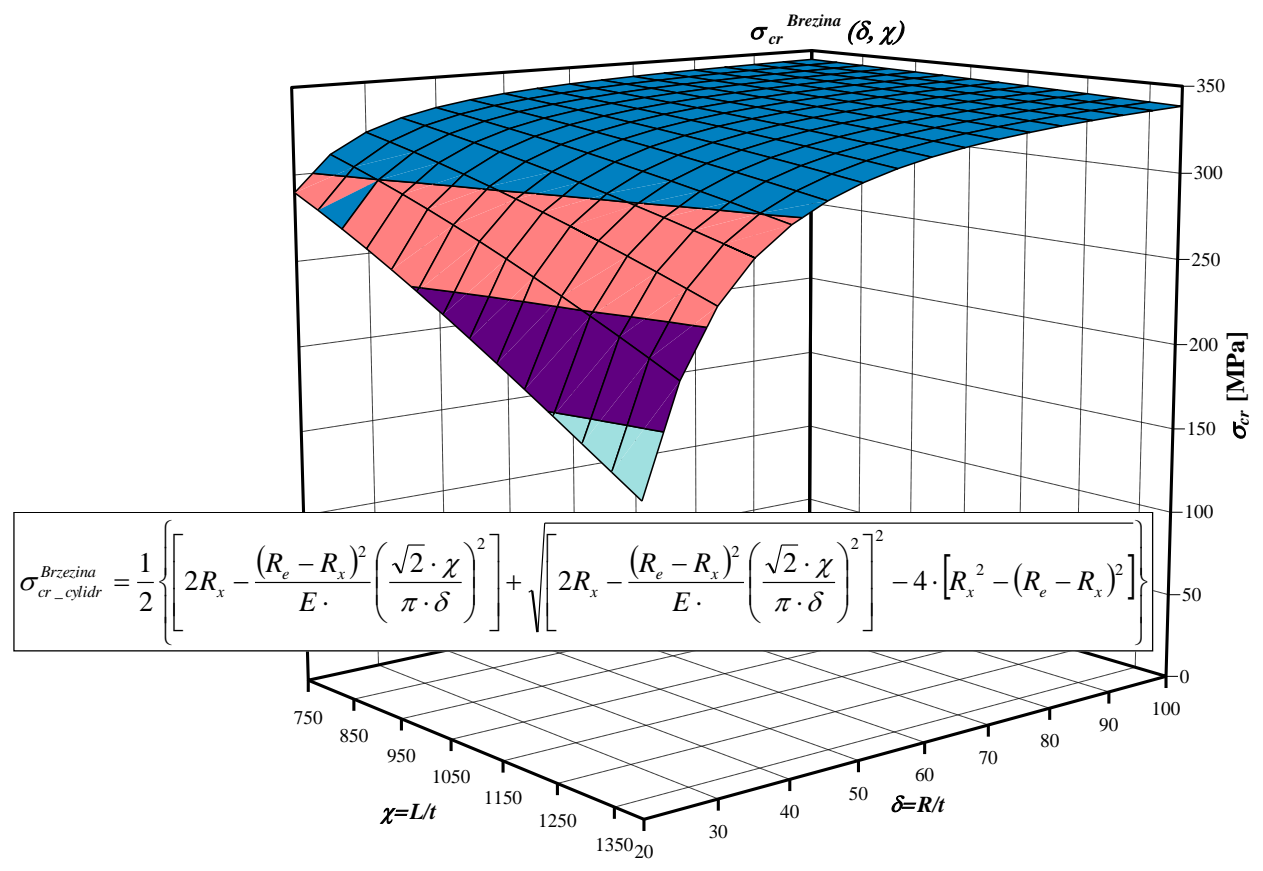

Fig. 8: Surface function $\sigma^{\text {Brzezina }}{ }_{c_{-}-c y l i n d r}(\delta, \chi)$ based on the Březina's formula of the cylindrically-shaped columns made of steel R35 compressed by ball-and-socket joints

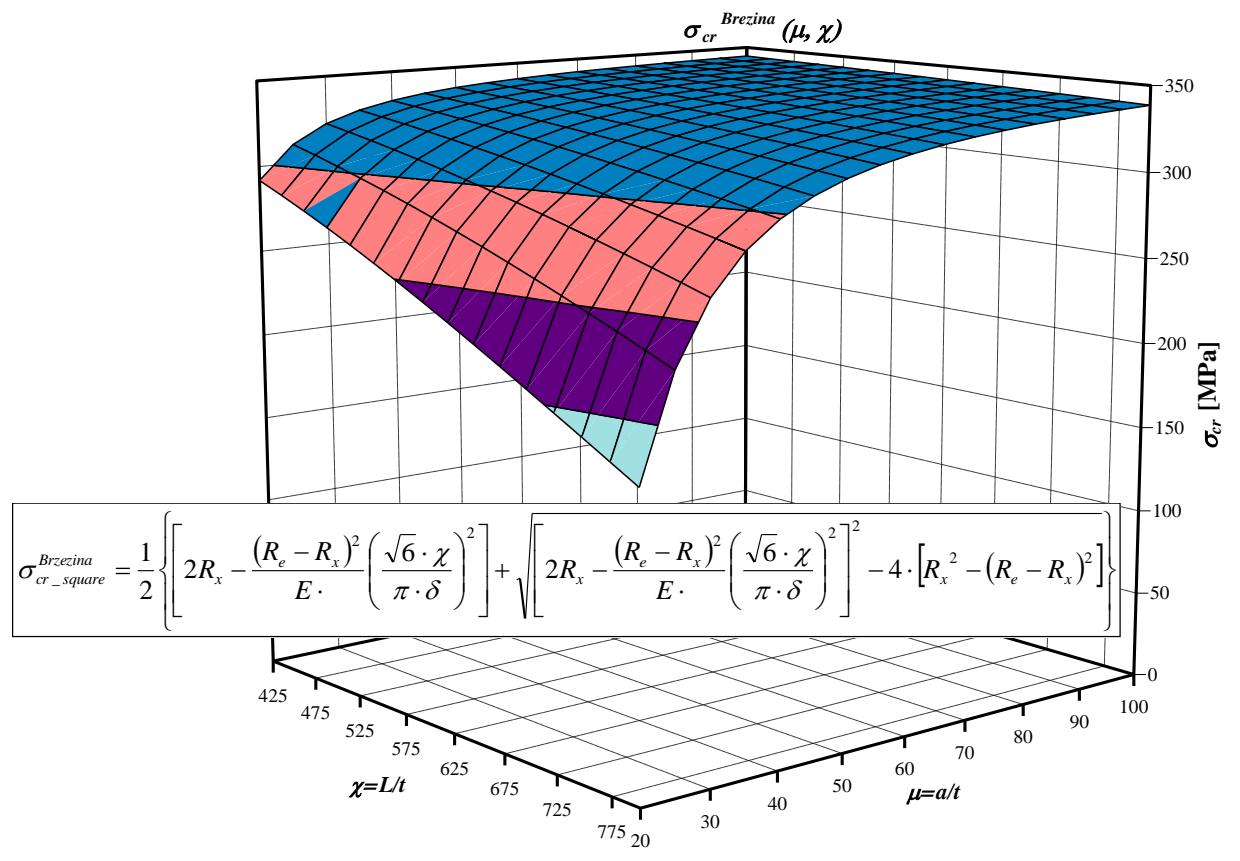

Fig. 9: Surface function $\sigma^{\text {Brzezina }}{ }_{c r}$ square $(\mu, \chi)$ based on the Březina's formula of the square-shaped columns made of steel R35 compressed by ball-and-socket joints

Pearson, (Bleich, 1952; Vol'mir, 1965) used in their research the combination of the tangent modulus $E_{t}$ and the modulus $E$ :

$$
\sigma_{c r}^{\text {Pearson-Bleich-Vol'mir }}=\left(\frac{\pi}{\lambda}\right)^{2} \sqrt{E \cdot E_{t}} .
$$


Using the function $\sigma(\varepsilon)$ according to the (Standard DIN 4114, 1953), Equation (17), the root of this quadratic equation with respect to $\sigma_{c r}$ would be as follows:

$$
\sigma_{c r}^{\text {Pearson-Bleich-Vol'mir }}=\frac{R_{x}+\sqrt{R_{x}^{2}-\left[\frac{\left(R_{e}-R_{x}\right)^{2} \lambda^{4}}{\pi^{4} \cdot E^{2}}+1\right] \cdot\left[R_{x}^{2}-\left(R_{e}-R_{x}\right)^{2}\right]}}{\left[\frac{\left(R_{e}-R_{x}\right)^{2} \lambda^{4}}{\pi^{4} \cdot E^{2}}+1\right]} .
$$

For the semi-slender thin-walled cylindrical column axially compressed by ball-and-socket joints the critical stress, according to Pearson-BleichVol'mir is equal to (Fig. 10):

$$
\sigma_{\text {cr_cylinder }}^{\text {Pears-Blich-Vol'mir }}=\frac{R_{x}+\sqrt{R_{x}^{2}-\left[\frac{\left(R_{e}-R_{x}\right)^{2} \cdot 4 \cdot \chi^{4}}{\pi^{4} \cdot \delta^{4} \cdot E^{2}}+1\right] \cdot\left[R_{x}^{2}-\left(R_{e}-R_{x}\right)^{2}\right]}}{\left[\frac{\left(R_{e}-R_{x}\right)^{2} \lambda^{4}}{\pi^{4} \cdot \delta^{4} \cdot E^{2}}+1\right]} .
$$

For the semi-slender thin-walled square column axially compressed by ball-and-socket joints the critical stress, according to Pearson-Bleich-Vol'mir's is equal to (Fig. 11):

$$
\sigma_{\text {cr__square }}^{\text {Pearson-Blech-Vol,mir }}=\frac{R_{x}+\sqrt{R_{x}^{2}-\left[\frac{\left(R_{e}-R_{x}\right)^{2} \cdot 36 \cdot \chi^{4}}{\pi^{4} \cdot \mu^{4} \cdot E^{2}}+1\right] \cdot\left[R_{x}^{2}-\left(R_{e}-R_{x}\right)^{2}\right]}}{\left[\frac{\left(R_{e}-R_{x}\right)^{2} \cdot 36 \cdot \chi^{4}}{\pi^{4} \cdot \mu^{4} \cdot E^{2}}+1\right]} .
$$

The secant modulus $E_{s}$ was used by (Stowell, 1948; Bijlaard, 1949; Broszko, 1953; Gerard, 1957; Vol'mir, 1965):

$$
\sigma_{c r}^{\text {Stowell-Bijlaard-Broszko-Gerard-Vol'mir }}=\left(\frac{\pi}{\lambda}\right)^{2} E_{s}
$$

The combination of the tangent modulus $E_{t}$ and the secant modulus $E_{s}$ used (Gerard, 1962):

$$
\sigma_{c r}^{\text {Gerard }}=\left(\frac{\pi}{\lambda}\right)^{2} \sqrt{E_{s} \cdot E_{t}}
$$

Stowell (1948; Bijlaard, 1949) used the combination of the tangent modulus $E_{t}$, a secant modulus $E_{s}$ and parameters:

$$
\sigma_{c r}^{\text {Stowell-Bijlaard }}=\left(\frac{\pi}{\lambda}\right)^{2} E_{s}\left(0.33+0.67 \sqrt{0.25+0.75 \frac{E_{t}}{E_{s}}}\right),
$$

as well as Gerard and Becker (1957): $\sigma_{c r}^{\text {Gerard-Becker }}=\left(\frac{\pi}{\lambda}\right)^{2} E_{s}\left(0.5+0.5 \sqrt{0.25+0.75 \frac{E_{t}}{E_{s}}}\right)$.

The combination of the tangent modulus $E_{t}$, the secant modulus $E_{s}$ and Young's modulus $E$ used (Radhakrishnan, 1956):

$\sigma_{c r}^{\text {Radhakrishnan }}=\left(\frac{\pi}{\lambda}\right)^{2} E \sqrt{\frac{E_{t}}{E_{s}}}$

and (Seide et al., 1960):

$\sigma_{c r}^{\text {Weingarten }}=\left(\frac{\pi}{\lambda}\right)^{2} E_{s} \sqrt{\frac{E_{t}}{E}}$.

The formulas passed in these works give the ambiguous, i.e., a possibility of different results in dependence on received experimental values $E_{t}$ or $E_{s}$. Therefore, applying these formulas wakes reservations.

The determining the function $E_{t}(\lambda)$ on the basis of a non-linear range of the $\sigma(\varepsilon)$ course obtained during the extension test of one normative specimen or as the standard like also wakes the reservations.

\section{Elastic-Plastic Stability of Semi-Slender Columns in Own Investigations}

The author did his own analysis of stability of thinwalled columns (Murawski, 1998; 2002a; 2002b; 2003; 2008a; 2008b; 2011a; 2011b; 2011c; 2017; 2018)

In case of stability of columns in elastic states the author assumed that the loss of stability occurs already at minimum loads, whereas the position of the resultant neutral layer caused by the superposition of pure compression and bending of the elastic line of the column is changing.

But for the loss of carrying capacity is responsible the position of a force line in relation to the critical transverse cross-section outline.

If the force line goes throw the inside of the critical cross-section, the moments of inside forces in this section are in equilibrium.

When the force line exits the critical cross-section outline, the equilibrium of the moments disappear and the column losses the carrying capabilities.

In case of stability of columns in elastic-plastic states the author assumed, that the column loses the stability when the force line enters the plastic zone in the critical transverse cross-section.

\section{Approximated Theory of Technical Stability for} Semi-Slender Columns in Elastic-Plastic States

This theory can be also named as the modified Engesser-Kármán-Shanley’s theory. 


$$
\sigma_{c r}^{P-B-V}(\delta, \chi)
$$

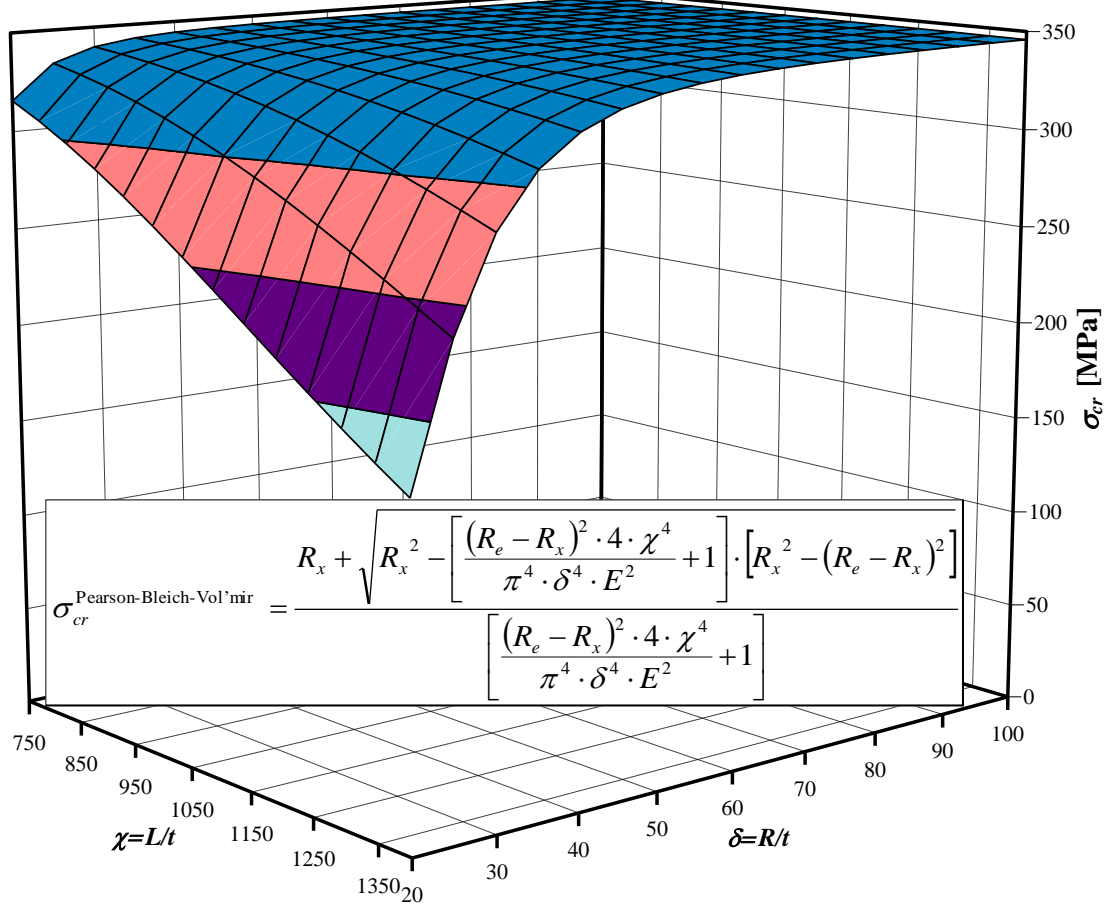

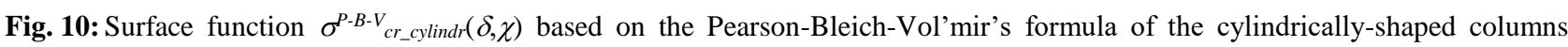
made of steel R35 compressed by ball-and-socket joints

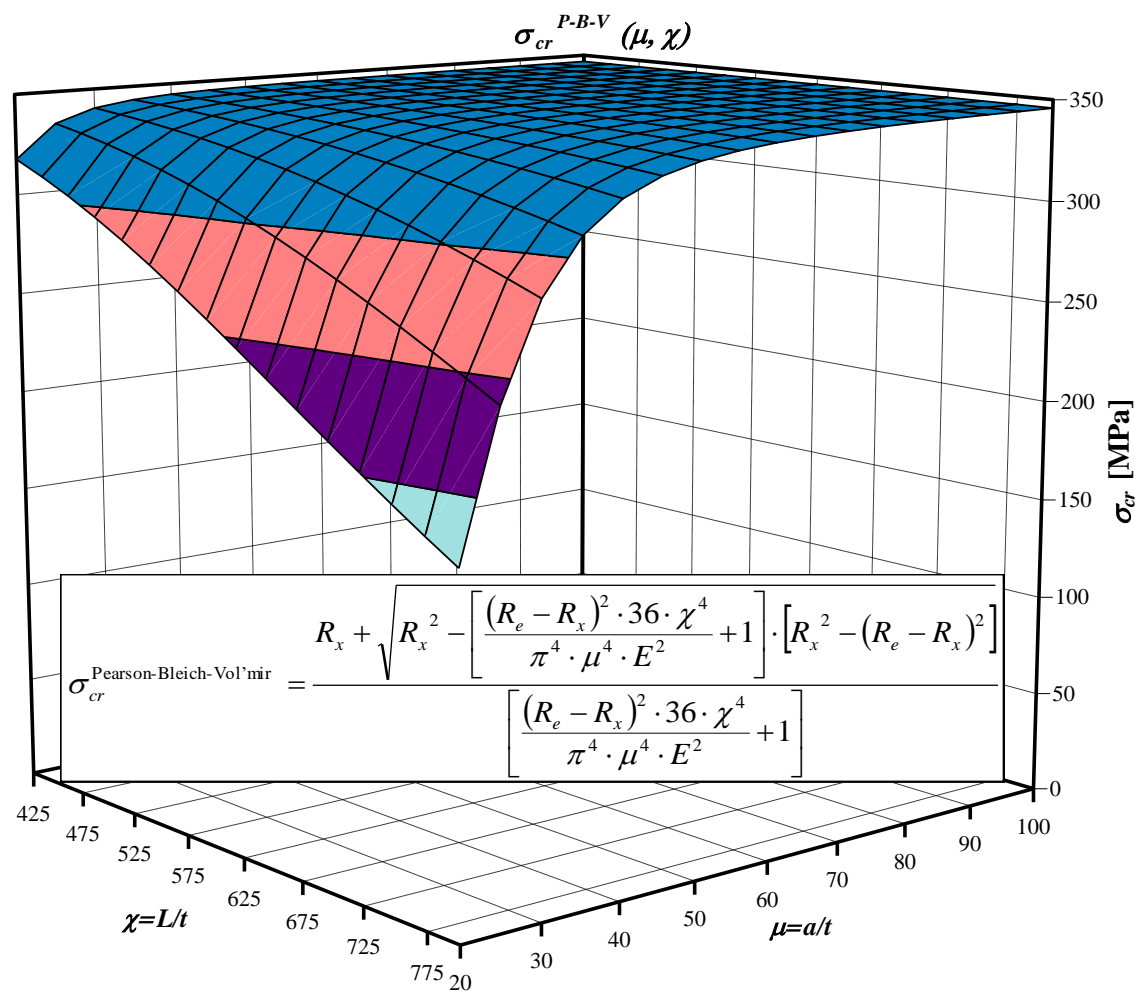

Fig. 11: Surface function $\sigma^{P-B-V_{c r} \text { square }}(\mu, \chi)$ based on the Pearson-Bleich-Vol'mir's formula of the square-shaped columns made of steel R35 compressed by ball-and-socket joints 
According to the assumption the state of stresses in the critical cross-section after the loss of stability and before the loss of carrying capacity results from the superposition of pure compression and bending. The modified Engesser-Kármán-Shanley's theory was described in the works (Murawski, 2008a; 2011a; 2011b; 2011c; 2017; 2018).

The formulas for the Engesser-Kármán critical stress are as follows:

$\sigma_{H}^{K M}(\lambda)=R_{H}^{E u}+\left(\frac{\lambda_{e l \_l t}-\lambda}{\lambda_{e l_{-} l t}}\right)\left[R_{H}^{*}-R_{H}^{E u}\right]$,

The $R_{e}{ }^{*}$ is attained for $\lambda_{0}$, i.e., $\sigma_{c r}(\lambda=0)=R_{e}{ }^{*}$ and $R_{H}^{E u}$ is attained for $\lambda_{e l \_l t}$, i.e., $\sigma_{c r}\left(\lambda_{e l_{l} l t}\right)=R_{H}^{E u}$.

If in the range $\left(\lambda_{0}, \lambda_{e l \_l t}\right)$ instead of $R_{H}{ }^{E u}$ we use the linear function $\sigma_{H}{ }^{K M}(\lambda)$, then similarly the compressive stress $\sigma_{c r}{ }^{K M}$ from the range $\left(\lambda_{0}, \lambda_{e l \_l t}\right)$ is attained for the slenderness ratio as follows:

$\sigma_{c r}^{K M}(\lambda)=\sigma_{H}^{K M}(\lambda)+\frac{\lambda_{e l \_l t}-\lambda}{\lambda_{e l_{-} l t}}\left[R_{e}^{*}-\sigma_{H}^{K M}(\lambda)\right]$,

hence, after taking into account Equation (32):

$$
\begin{aligned}
& \sigma_{c r}^{K M}(\lambda)=R_{H}^{E u}+\left(\frac{\lambda_{e l_{-l t}}-\lambda}{\lambda_{e l_{-} l t}}\right)\left[R_{H}^{*}-2 R_{H}^{E u} R_{\mathrm{e}}^{*}\right] \\
& +\left(\frac{\lambda_{\text {el_lt }}-\lambda}{\lambda_{\text {el_lt }}}\right)^{2}\left[R_{H}^{*}-R_{H}^{E u}\right] .
\end{aligned}
$$

If $R_{H}^{E u}=\sigma_{H}\left(\lambda_{e l \_l t}\right)=\sigma_{c r}\left(\lambda_{e l \_l t}\right)$ denotes the elasticity limit used in Euler's formula to determine $\lambda_{e l \_l t}$ :

$$
\lambda_{e l_{-} t t}^{E u}=\pi \sqrt{\frac{E}{R_{H}^{E u}}}
$$

then after inserting Equation (31) in Equation (32):

$$
\begin{aligned}
& \sigma_{c r}(\lambda)=\left(1-\frac{\lambda}{\lambda_{e l_{-} t}}\right)\left(R_{e}^{*}+R_{H}^{*} \frac{\lambda}{\lambda_{e l_{-} t}}\right)+R_{H}^{E u}\left(\frac{\lambda}{\lambda_{e l_{-} t}}\right)^{2} . \\
& \sigma_{c r}(\lambda)=\left(\frac{\lambda_{e l_{\perp}-l t}-\lambda}{\lambda_{e l_{-} t}-\lambda_{1}}\right)\left(R_{e}^{*}+R_{H}^{*} \frac{\lambda}{\lambda_{e l_{-} t t}-\lambda_{1}}\right)+R_{H}^{E u}\left(\frac{\lambda}{\lambda_{e l_{-} t t}-\lambda_{1}}\right)^{2} .
\end{aligned}
$$

After the insertion of Euler's formula, we obtain:

$$
\sigma_{H}^{K M}(\lambda)=\left(\frac{\pi}{\lambda_{e l \_l t}}\right)^{2} E+\left(1-\frac{\lambda}{\lambda_{e l_{-} l t}}\right)\left[R_{H}^{*}-\left(\frac{\pi}{\lambda_{e l_{-} l t}}\right)^{2} E\right],
$$

$\sigma_{c r}^{K M}(\lambda)=\left(1-\frac{\lambda}{\lambda_{e l_{-} l t}}\right)\left(R_{e}^{*}+R_{H}^{*} \frac{\lambda}{\lambda_{e l_{-} l t}}\right)+E\left(\frac{\pi \lambda}{\lambda_{\lambda_{l_{l} \_l}^{2}}^{2}}\right)^{2}$.

or:

$$
\begin{aligned}
& \sigma_{H}^{K M}(\lambda)=R_{H}^{E u}+\left(1-\frac{\lambda}{\pi} \sqrt{\frac{R_{H}^{E u}}{E}}\right)\left[R_{H}^{*}-R_{H}^{E u}\right], \\
& \sigma_{c r}^{K M}(\lambda)=\left(1-\frac{\lambda}{\pi} \sqrt{\frac{R_{H}^{E u}}{E}}\right)\left(R_{e}^{*}+R_{H}^{*} \frac{\lambda}{\pi} \sqrt{\frac{R_{H}^{E u}}{E}}\right)+\frac{1}{E}\left(\frac{\lambda}{\pi} R_{H}^{E u}\right)^{2} .
\end{aligned}
$$

In case of the semi-slender thin-walled cylindrical column compressed by ball-and-socket joints the elastic stress is as follows (Fig. 12):

$$
\sigma_{H_{-} \text {cylinder }}^{K M}(\lambda)=\left(\frac{\pi}{\lambda_{e L_{-} t}}\right)^{2} E+\left(1-\frac{\sqrt{2} \cdot \chi}{\lambda_{e L_{-} t} \cdot \delta}\right)\left[R_{H}^{*}-\left(\frac{\pi}{\lambda_{e l_{-} t}}\right)^{2} E\right] \text {, }
$$

and the critical stress (Fig. 13):

$$
\sigma_{c r}^{K M}(\lambda)=\left(1-\frac{\sqrt{2} \cdot \chi}{\lambda_{e l_{-l t}} \cdot \delta}\right)\left(R_{e}^{*}+R_{H}^{*} \frac{\sqrt{2} \cdot \chi}{\lambda_{e l_{-l t}} \cdot \delta}\right)+E\left(\frac{\pi \cdot \sqrt{2} \cdot \chi}{\lambda_{e l_{-l t}}^{2} \cdot \delta}\right)^{2} .
$$

In case of the axially compressed semi-slender thinwalled square column by ball-and-socket joints the elastic stress is as follows (Fig. 14):

$$
\sigma_{H_{-} \text {square }}^{K M}(\lambda)=\left(\frac{\pi}{\lambda_{e l_{-l t}}}\right)^{2} E+\left(1-\frac{\sqrt{6} \cdot \chi}{\lambda_{e l_{-l t}} \cdot \mu}\right)\left[R_{H}^{*}-\left(\frac{\pi}{\lambda_{e l_{-l t}}}\right)^{2} E\right] \text {, }
$$

and the critical stress (Fig. 15):

$$
\sigma_{c r_{-} \text {square }}^{K M}(\lambda)=\left(1-\frac{\sqrt{6} \cdot \chi}{\lambda_{e l_{-l t}} \cdot \mu}\right)\left(R_{e}^{*}+R_{H}^{*} \frac{\sqrt{6} \cdot \chi}{\lambda_{e l_{l} l t} \cdot \mu}\right)+E\left(\frac{\pi \cdot \sqrt{6} \cdot \chi}{\lambda_{e l_{l} t}^{2} \cdot \mu}\right)^{2},
$$

where, $\delta=R / t, \mu=a / t$ and $\chi=L / t$.

The graphs for the columns made of steel R35 were determined from the author's studies (Murawski, 1998; 2003; 2004).

The following values were assumed by the author: for steel R35 (Standards: PN-73/H-74240, PN-75/H84019): $R_{e}{ }^{*}=346.54 \mathrm{MPa}, R_{H}{ }^{*}=268.24 \mathrm{MPa}, R_{H}{ }^{E u}=$ $156 \mathrm{MPa}, E=166614 \mathrm{MPa}, \lambda_{\text {el_lt }}=102.6$ (Fig. 16).

In order to compare the results of the author's approximated hypothesis with others simplifications and hypothesis-their results in the case of columns made of the steel R35 were determined and shown as the graphs of the functions $\sigma_{c r}(\lambda)$ in Figs. 17 to 21 . 


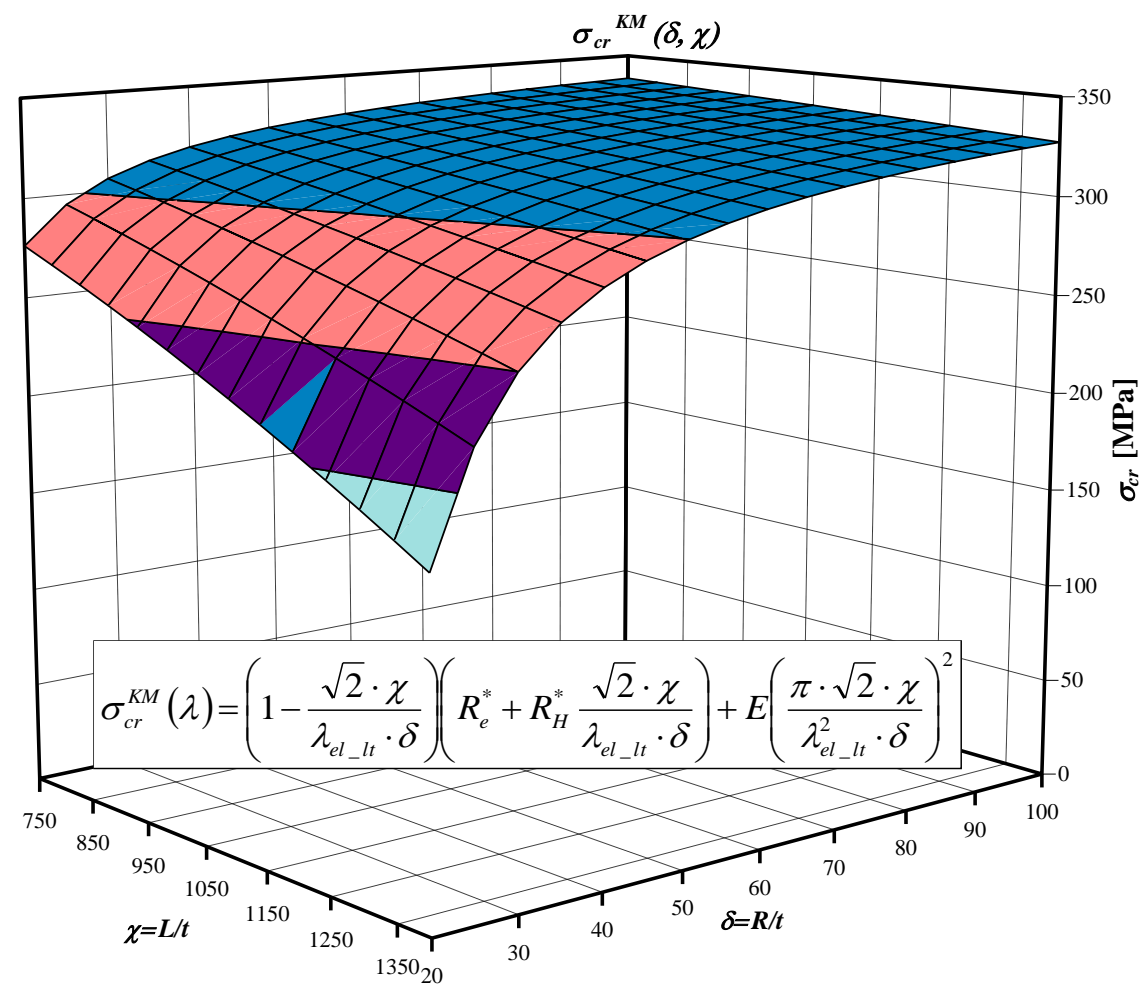

Fig. 12: Surface function $\sigma_{c r}{ }^{K M}{ }_{c y l i n d r}(\delta, \chi)$ based on the author's formula of the cylindrically-shaped columns made of steel R35 compressed by ball-and-socket joints

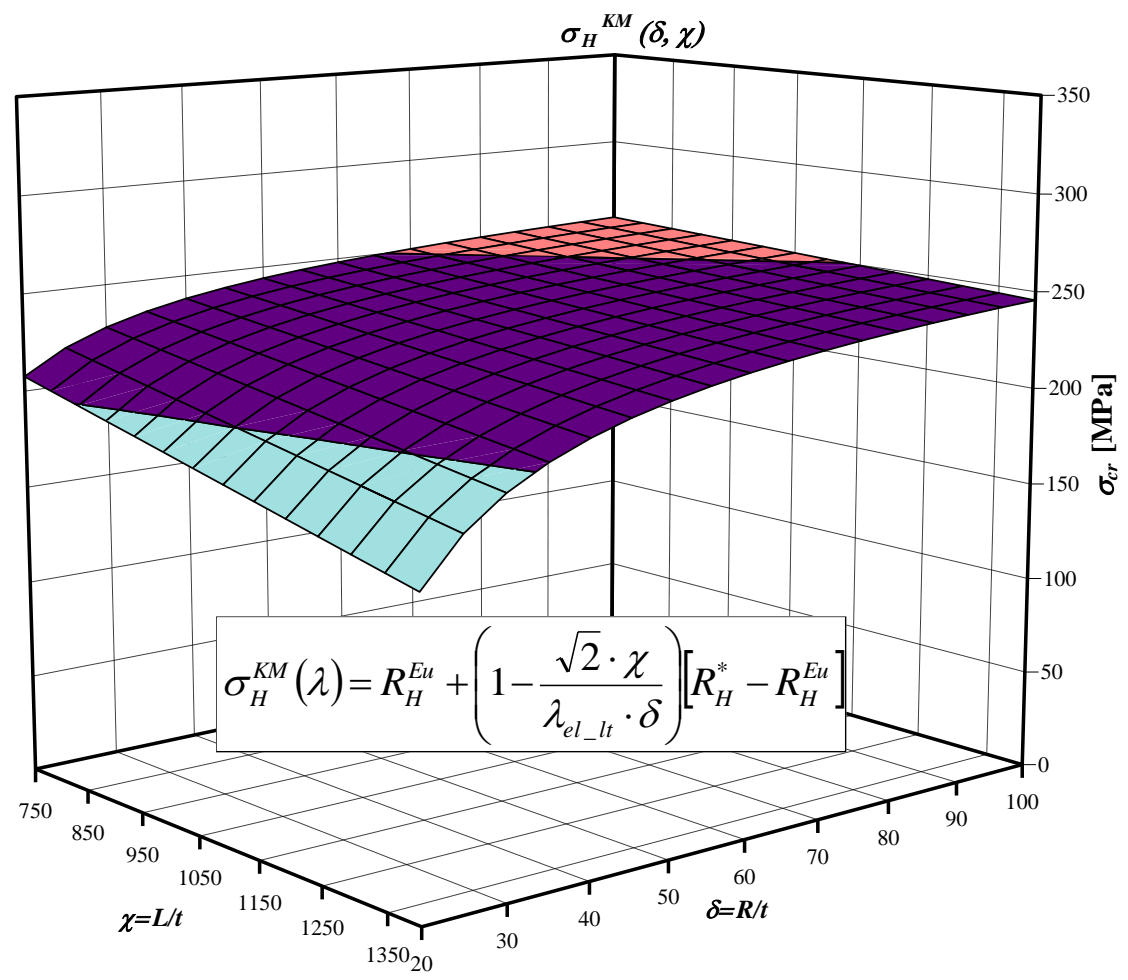

Fig. 13: Surface function $\sigma_{H}{ }^{K M}$ cylindr $(\delta, \chi)$ based on the author's formula of the cylindrically-shaped columns made of steel R35 compressed by ball-and-socket joints 


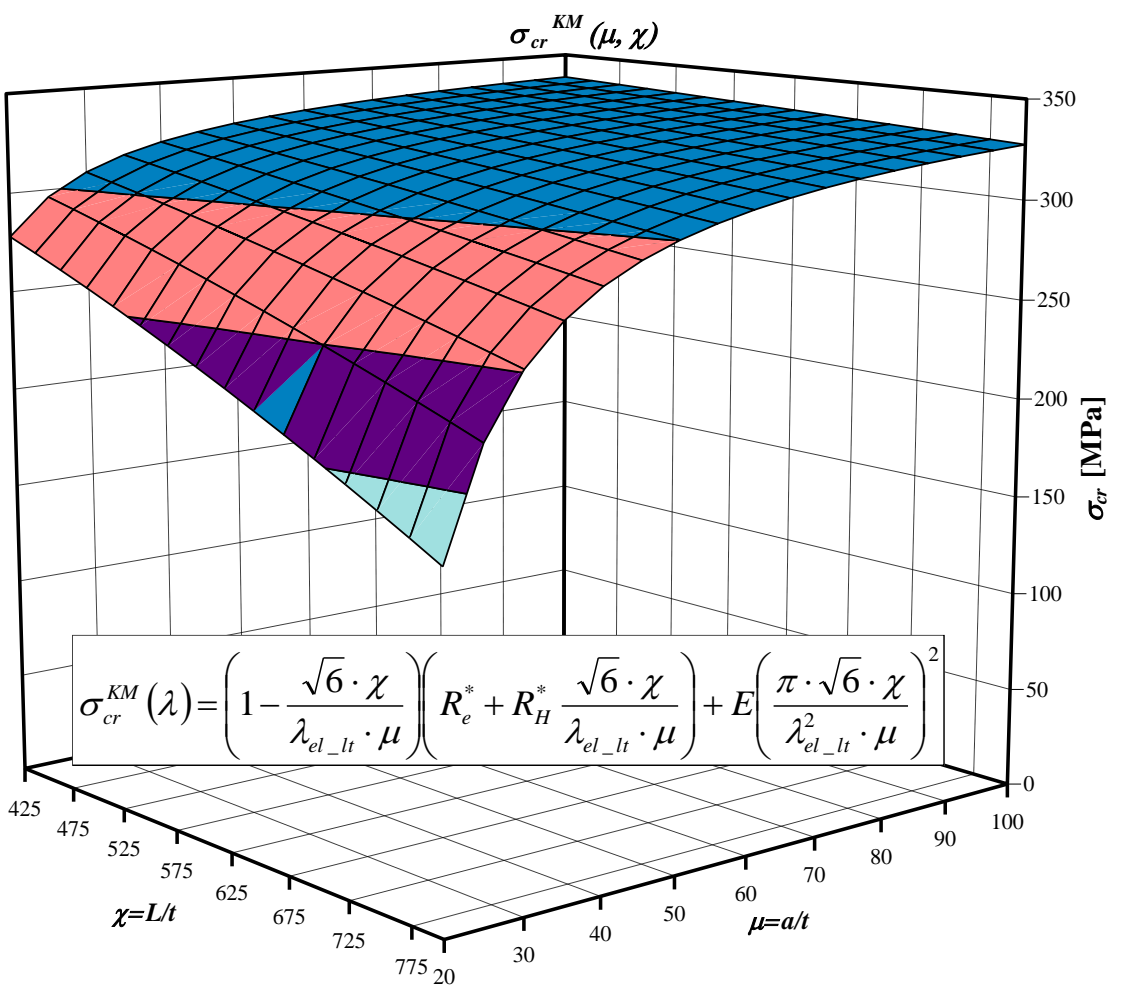

Fig. 14: Surface function $\sigma_{c r}{ }^{K} M_{\text {square }}(\mu, \chi)$ based on the author's formula of the square -shaped columns made of steel R35 compressed by ball-and-socket joints

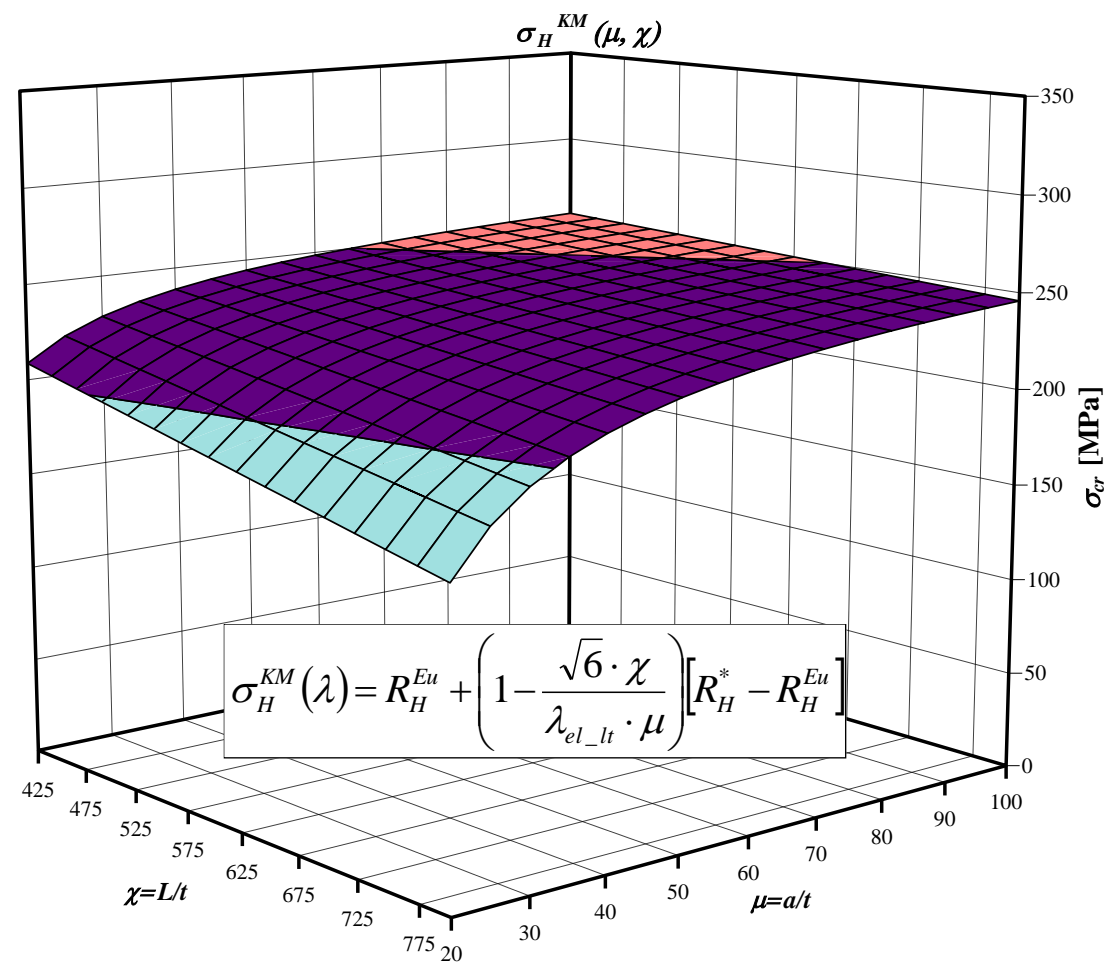

Fig. 15: Surface function $\sigma_{H}{ }^{K M}$ square $(\mu, \chi)$ based on the author's formula of the square-shaped columns made of steel R35 compressed by ball-and-socket joints 


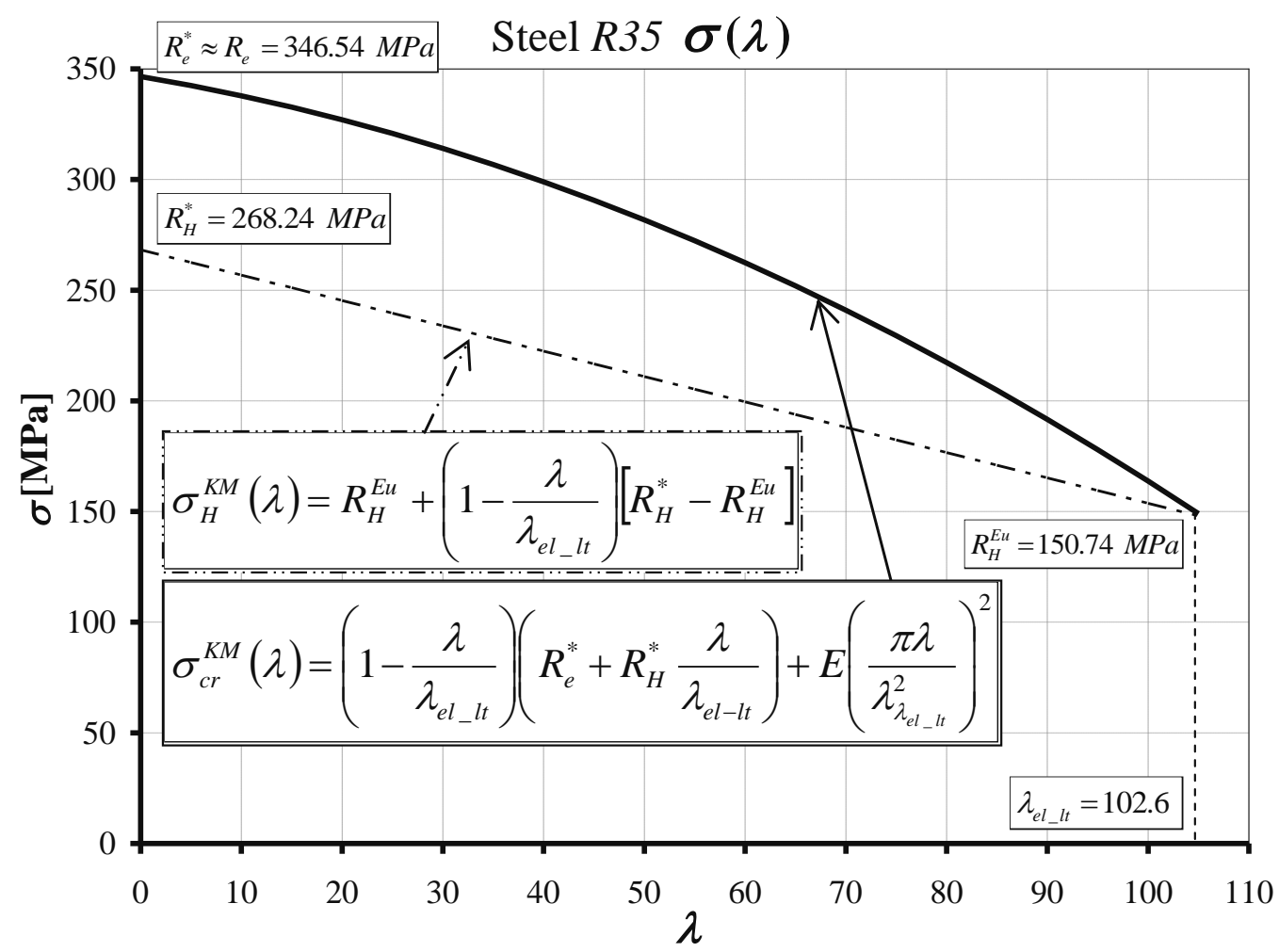

Fig. 16: Functions $\sigma_{c r}(\lambda)$ for columns made of steel R35 according to the modified Engesser-Kármán-Shanley’s hypothesis

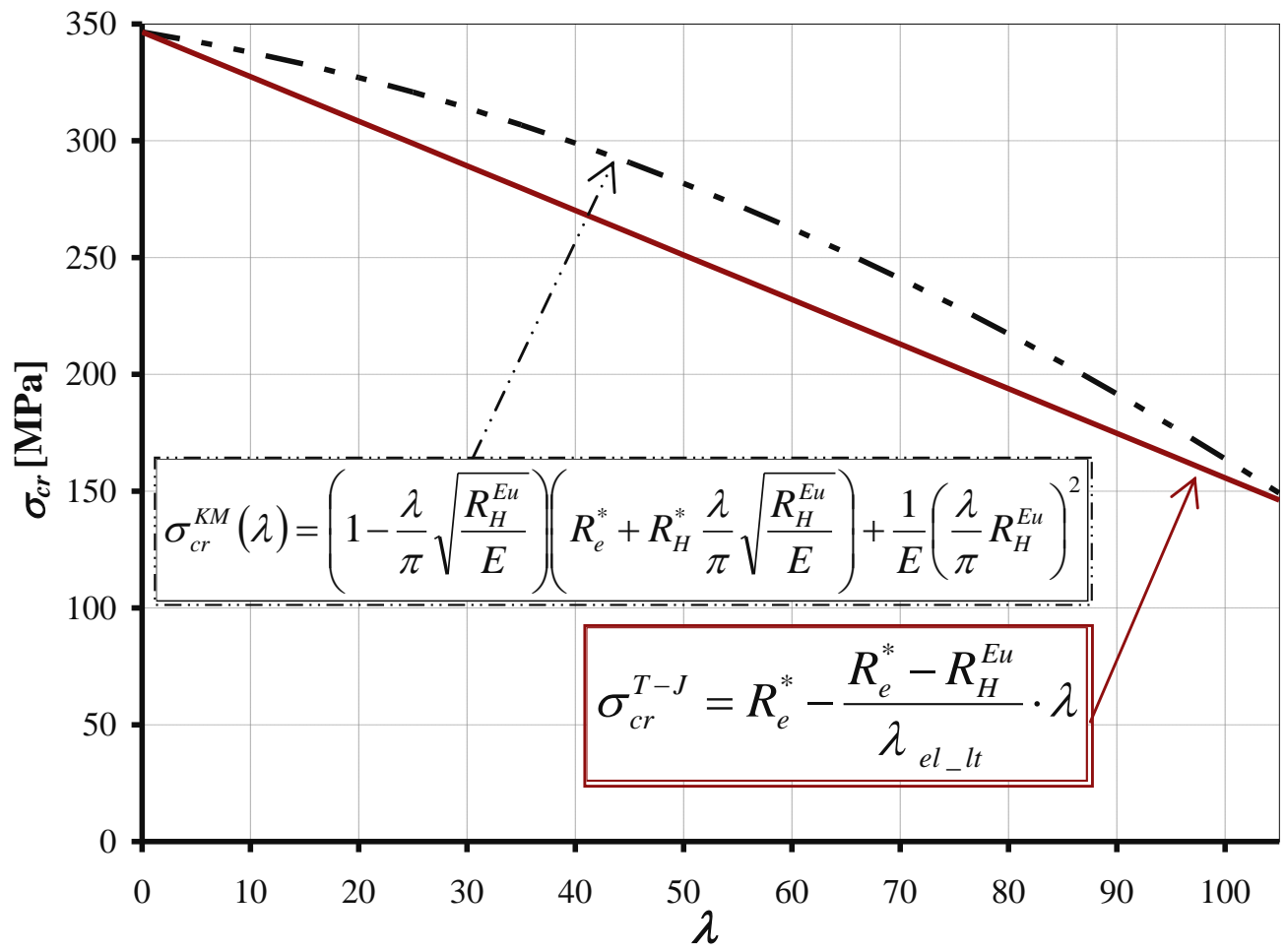

Fig. 17: Functions $\sigma_{c r}(\lambda)$ for columns made of steel R35 according to the modified Engesser-Kármán-Shanley’s hypothesis and to the Tetmajer-Jasiński's simplification 


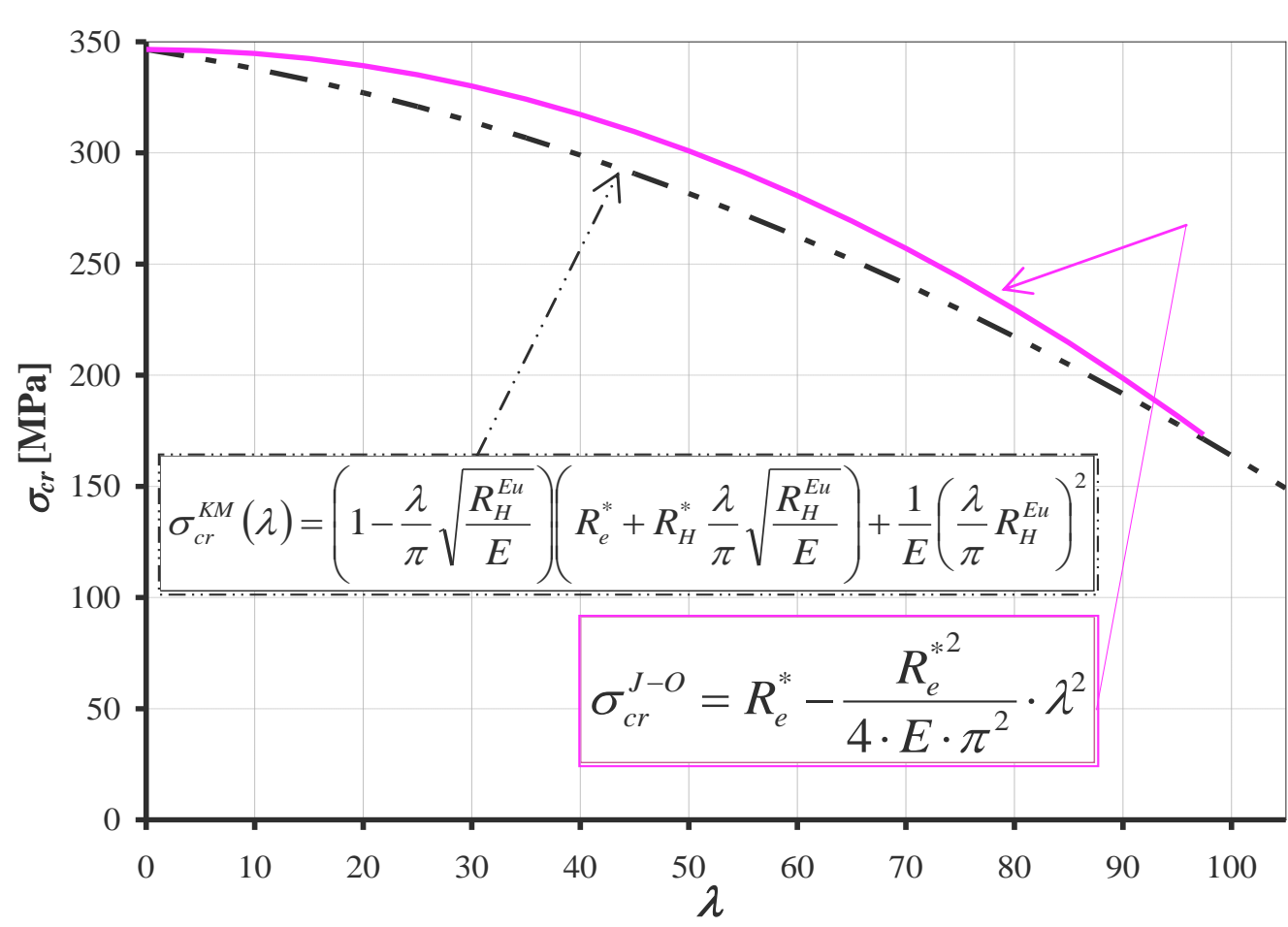

Fig. 18: Functions $\sigma_{c r}(\lambda)$ for columns made of steel R35 according to the modified Engesser-Kármán-Shanley’s hypothesis and to the Johnson-Ostenfeld's simplification

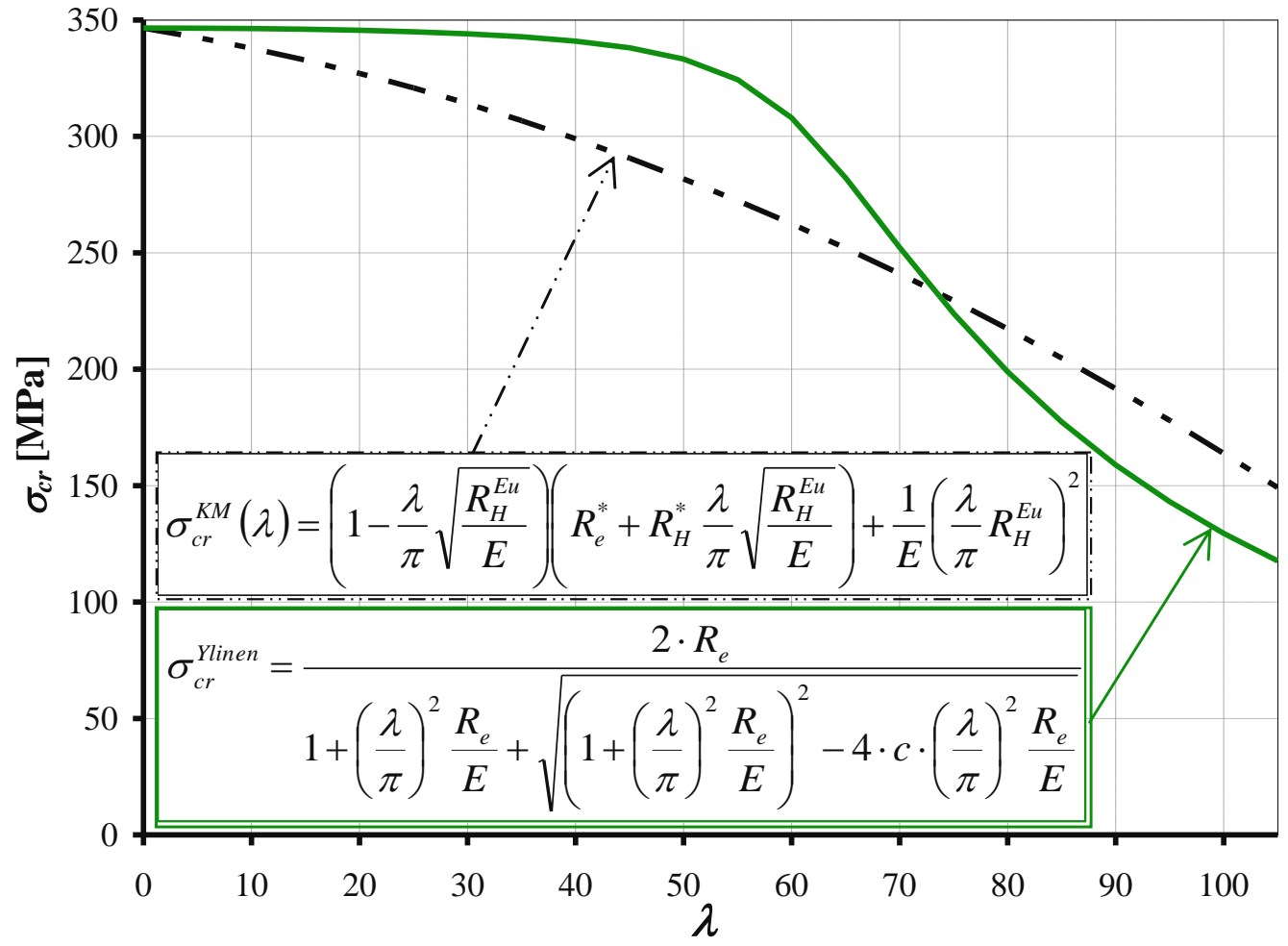

Fig. 19: Functions $\sigma_{c r}(\lambda)$ for columns made of steel R35 according to the modified Engesser-Kármán-Shanley’s hypothesis and to the Ylinen's hypothesis 


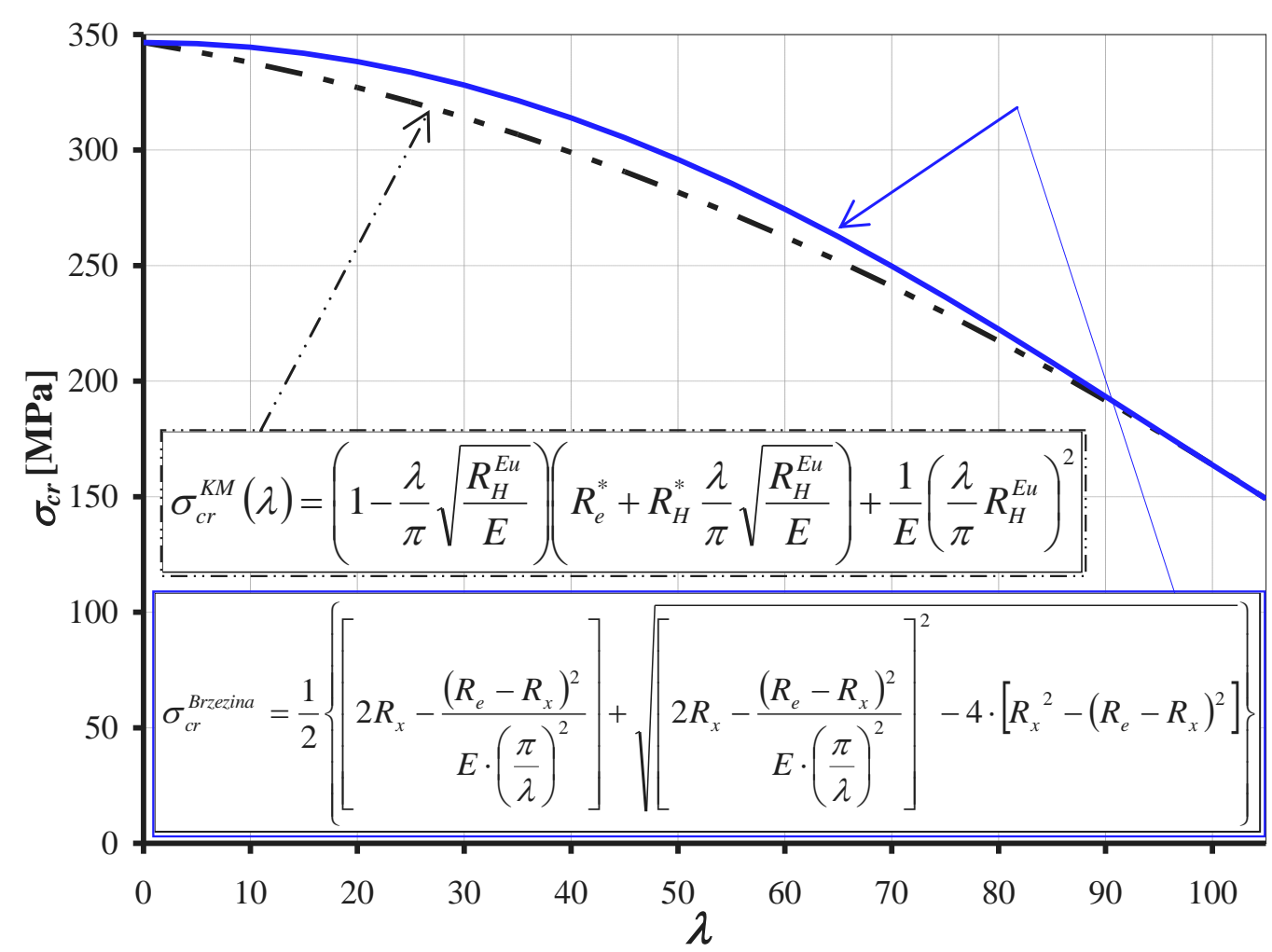

Fig. 20: Functions $\sigma_{c r}(\lambda)$ for columns made of steel R35 according to the modified Engesser-Kármán-Shanley's hypothesis and to Březina's hypothesis

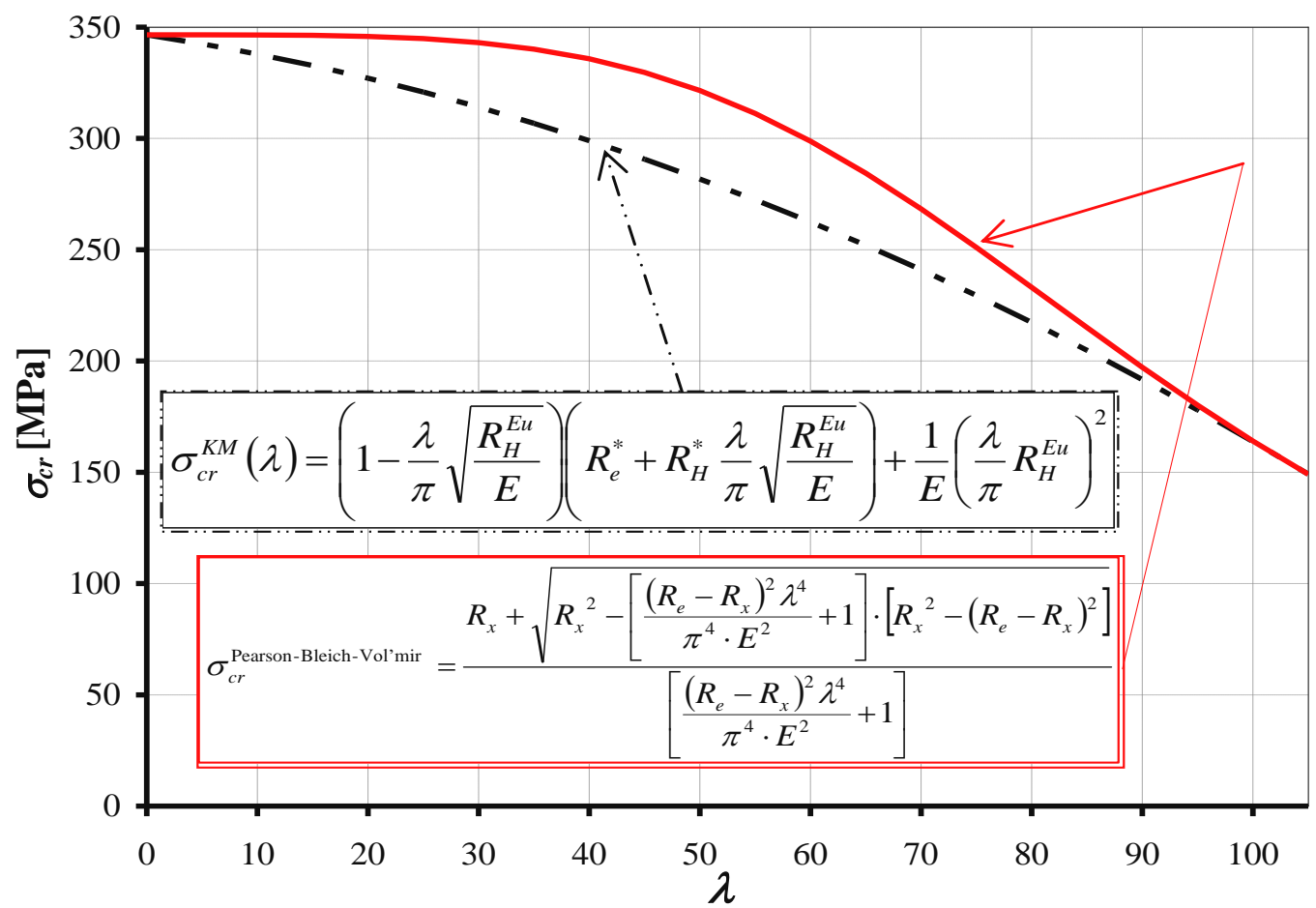

Fig. 21: Functions $\sigma_{c r}(\lambda)$ for columns made of steel R35 according to the modified Engesser-Kármán-Shanley's hypothesis and to Pearson (1950)-Bleich (1952)-Vol'mir (1965)'s hypothesis 


\section{Discussion}

The Tetmajer-Jasiński's surface Equation (4) and (5) shown in Figs. 1 and 2 are linearly decreasing with the $\chi$ ratio and strongly non-linearly with second degree increasing with $\delta$ or $\mu$ ratio.

The Johnson-Ostenfeld's surface Equation (8) and (9) shown in Figs. 3 and 4 are slightly non-linearly decreasing with the $\chi$ ratio and strongly non-linearly with second degree increasing with $\delta$ or $\mu$ ratio.

The Ylinen's surface Equation (15) and (16) shown in Figs. 6 and 7 are strong non-linear with the third degree, with 2 points of changing of inclinations, of decreasing with the $\chi$ ratio and very strong hyperbolic non-linearly increasing with $\delta$ or $\mu$ ratio, so big part of the surface function is almost flat.

The Březina's surface Equation (20) and (21) shown in Figs. 8 and 9 are almost linearly decreasing with the $\chi$ ratio and strongly non-linearly with second degree of increasing with $\delta$ or $\mu$ ratio.

The Pearson-Bleich-Vol'mir's surface Equation (24) and (25) shown in Figs. 10 and 11 are slightly non-linear with the second degree of decreasing with the $\chi$ ratio and hyperbolic non-linear of increasing with $\delta$ or $\mu$ ratio, so a part of the surface function is almost flat.

The author's surface Equation (42) and (44) for the limiting elastic stress shown in Figs. 13 and 15 are linear decreasing with the $\chi$ ratio and slightly non-linear increasing with $\delta$ or $\mu$ ratio, so a big part of the surface function is almost flat.

The author's surface Equation (43) and (45) for the critical compressive stress shown in Figs. 12 and 14 are linearly decreasing with the $\chi$ ratio and non-linearly with second degree of increasing with $\delta$ or $\mu$ ratio, so a part of the surface function is almost flat.

In order to compare the results of the author's approximated hypothesis, i.e., the modified EngesserKármán-Shanley's hypothesis with others simplifications and hypotheses-their results in the case of columns made of the steel R35 were determined and shown for adequately ranges for elastic-plastic states as the graphs of the functions $\sigma \operatorname{cr}(\lambda)$ in Figs. 16 to 21. Because these functions are currently various then above differences absolute and relative are not connected.

In Fig. 16 is shown how are determined the parameters $R_{e}{ }^{*}$ - as the limit of the plastic stress $R_{e}$ but for $\lambda=0, R_{H}{ }^{*}$ - as the $R_{H}$ but for $\lambda=0$ and $R_{H}{ }^{E u}$ - as the limit of the elastic stress $R_{H}$ but for $\lambda=\lambda_{\text {el_ll }}$.

The maximal departures the results of those simplifications and hypotheses from the author's approximated hypothesis are presented in Table 1 .
Table 1: Maximal differences $\Delta[\%]$ between results obtained according to other simplifications and hypotheses and the author's approximated hypothesis

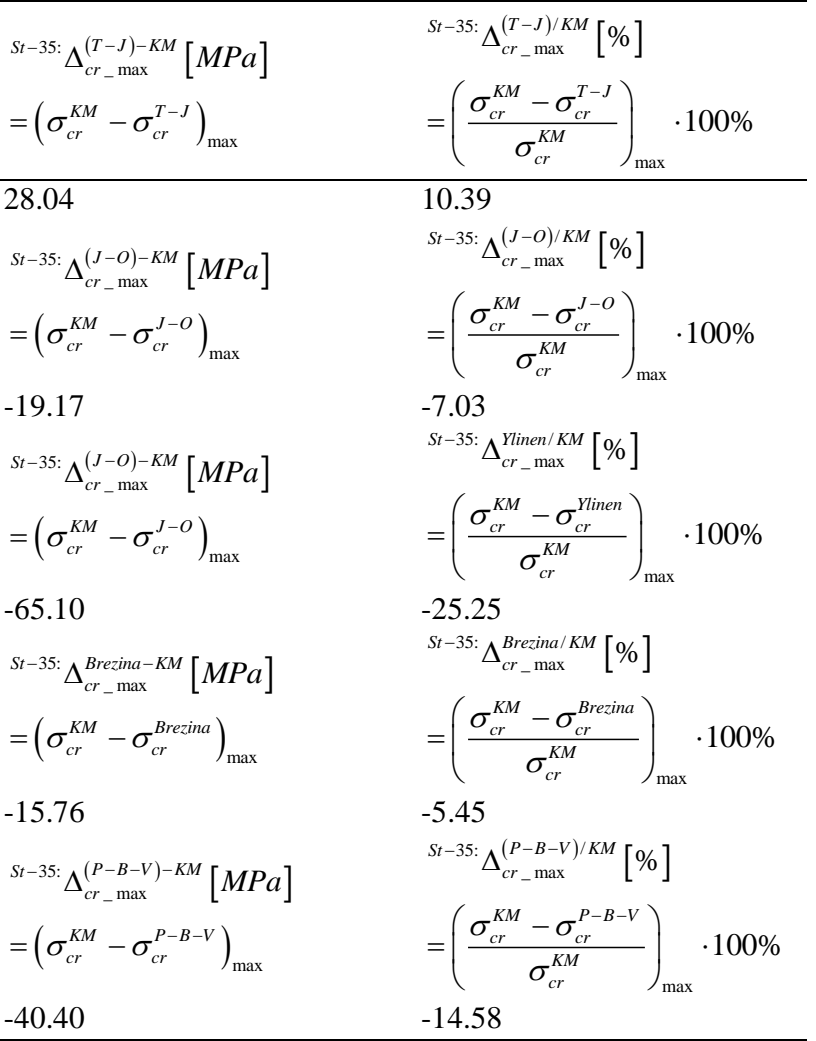

The biggest maximal differences are between the Ylinen's and approximated author's hypotheses: $-65,10$ $\mathrm{MPa}$ and $-25,25 \%$. The least maximal differences are between the Březina's simplification and author's approximated hypothesis: $-15,76 \mathrm{MPa}$ and $-5,45 \%$.

\section{Conclusion}

The surface functions for the Tetmajer-Jasiński's straight line, Johnson-Ostenfeld's parabola, Ylinen's, Březina's and Pearson-Bleich-Vol'mir's theories depending on $\delta=R / t$ and $\mu=a / t$ and $\chi=L / t$, for the same ranges of arguments-adequately for cylindrical and square columns made of steel R35, shown in Figs. 1 to 4 and Figs. 6 to 11, give a possibility to compare them in relation to the modified Engesser-Kármán-Shanley's theory with the surface functions shown in Figs. 12 to 15.

The review and analysis of those theories shows that those theories are rather pure, simplified and give limited, inaccurate results, e.g., the surface functions for the cylindrically-shaped and square-shaped columns are the same for adequately ranges for elastic-plastic states.

For the Johnson-Ostenfeld's, Ylinen's, Březina's and Pearson-Bleich-Vol'mir's theories the surface functions are almost flat in the most part-the blue parts of the surface functions in Figs. 3 and 4 and Figs. 6 to 11. 
The formulas given by those theories don't allow to present them depending on the transverse cross-section area $A$ and slenderness ratio $\lambda$ together. That proves that those theories are simplified and limited.

They don't allow to present the functions for the elastic limit stress, for what allows the approximated theory of technical stability for columns in elastic-plastic states, however this theory also gives big flat parts of the surface functions as well as doesn't allow to present it depending on the transverse cross-section area $A$ and slenderness ratio $\lambda$ together.

They don't allow to present the functions for the shell stresses and strains.

The theories basing on the tangent modulus $E_{t}$ and/or secant modulus $E_{s}$ can use the (Standard DIN 4114, 1953), but this standard is rather simplified and can be unsuitable for every case.

The comparison of results obtained from the simplifications and theories related to the modified Engesser-Kármán-Shanley's hypothesis gives departures between -25.25 and $+10.39 \%$. Naturally, those simplifications and theories should be also compared to experimental findings. The results of so comparison are presented in the paper (Murawski, 2020b).

\section{Funding}

No funding was received for this research study.

\section{Ethics}

The content of this paper is the changed preprint (Murawski, 2020a) according to the issuer requirements and the reviewers and own author's corrections.

The Author confirms that there is no conflict of interest.

\section{References}

Al-Kamal, M. K. (2017). Estimating Elastic Buckling Load for an Axially Loaded Column Bolted to a Simply Supported Plate using Energy Method. AlNahrain Journal for Engineering Sciences, 20(5), 1154-1159.

Alvarenga, A. R., \& Silveira, R. A. (2006). Considerations on advanced analysis of steel portal frames. In Proceedings of ECCM III European Conference on Computational Mechanics-Solids, Structures and Coupled Problems in Engineering (p. 2119).

Bijlaard, P. P. (1949). Theory and tests on the plastic stability of plates and shells. Journal of the Aeronautical Sciences, 16(9), 529-541.

Bleich, F. (1952). Buckling strength of metal structures. Mc Graw-Hill Book Company, Inc., Cardnr. 51-12588.
Brank, B., Perić, D., \& Damjanić, F. B. (1997). On large deformations of thin elasto-plastic shells: implementation of a finite rotation model for quadrilateral shell element. International Journal for Numerical Methods in Engineering, 40(4), 689-726.

Březina, V., \& Wiesławski, Z. (1966). Stateczność prętów konstrukcji metalowych. Arkady.

Broszko, M. (1953). Über die unelastische Knickung prismatischer Stäbe. Bull. Acad. Pol., Ser. Sci. Techn, 1(3), 71-74.

Dubina, D., \& Ungureanu, V. (2000). Elastic-plastic interactive buckling of thin-walled steel compression members.

Engesser, F. (1889). Ober Die Knickfestigkeit Gerader Stabe (On the Buckling Strength of Straight Struts) Zeitschrift fur Architektur und Ingenieurwesen.

Engesser, F. (1895). Über knickfragen (About bending problems). Schweizerische Bauzeitung, 26(4), 24-26.

Euler, L. (1744). Methodus inveniendi lineas curvas maximi minimive proprietate gaudentes. apud Marcum-Michaelem Bousquet.

Euler, L. (1759). Sur la force des colonnes. Memoires de l'Academie des Sciences de Berlin, 252-282.

Fraldi, M., Nunziante, L., Carannante, F., Prota, A., Manfredi, G., \& Cosenza, E. (2008). On the prediction of the collapse load of circular concrete columns confined by FRP. Engineering Structures, 30(11), 3247-3264.

Gerard, G. (1957). Plastic stability theory of thin shells. J. Aeron. Sci. 24 (4), 269-274.

Gerard, G. (1962). Plastic stability theory of geometrically orthotropic plates and cylindrical shells. Journal of the Aerospace Sciences, 29(8), 956-962.

Gerard, G., \& Becker, H. (1957). Handbook of structural stability. Part 1- Buckling of flat plates. Technical Note 3781, Natl. Advisory Committee for Aeronautics (NASA), Washinton DC.

Jasiński, F. S. (1894). On Longitudinal Bending Strength (in Russian), St. Petersburg.

von Kármán, T. (1908). Die knickfestigkeit gerader stäbe. Physikalische zeitschrift, 9(4), 136-140.

Kármán, T., (1910). Untersuchungen über Knickfestighkeit. Mitteilungen über Forschungsarbeiten auf dem Gebiete des Ingenieurwesens, 81, Berlin. https://link.springer.com/chapter/10.1007\%2F978-3662-01994-8_1

Krishan, A. L., Chernysova, E. P., \& Astafyeva, M. A. (2019, December). Behavior of compressed concrete in a glass fiber-reinforced shell. In IOP Conference Series: Materials Science and Engineering (Vol. 687, No. 3, p. 033034). IOP Publishing. 
Lepik, Ü. (1999). Bifurcation analysis of elastic-plastic cylindrical shells. International journal of non-linear mechanics, 34(2), 299-311.

Leoveanu, I. S. V., Kormanikova, E., Kotrasova, K., \& Taus, D. (2012). The Welding Technology Influence on the double $\mathrm{T}$ girder beams buckling. DOI, 10(2.1), 1295-2648.

Murawski, K. (1998). The Modelling of Energy Consuming Process in Layered Vehicles Bumper (in Polish), Doctor's thesis. Poznan University of Technology, Faculty of Hardworking Machines and Vehicles.

Murawski, K. (2002a). The Engesser-Shanley modified theory of stability of thin-walled cylindrical rods with example of use for steel St35. Acta Scientiarum Polonorum Architectura-Budownictwo, 1-2.

Murawski, K. (2002b). Stability analysis of a thin-walled plywood cylindrically shaped element. Annals of Warsaw Agricultural University, Forestry and Wood Technology, Special Number I, Warsaw Agricultural University Press, Warsaw, 230-234.

Murawski, K. (2003). Theory of stability of layered cylindrical rods in elasto-plastic states exemplified by steel R35. Electronic Journal of Polish Agricultural Universities, Civil Engineering, 2(6).

Murawski, K. (2004). The Euler's modified theory of stability with stresses and strains analysis on example of very slender cylindrical shells made of steel. Acta Scientiarum Polonorum, Architectura, 3(1), 2004.

Murawski, K. (2008a). Critical stressof squat cylindrical and square shaped plywood elements made of birch compressed by ball-and-socket joints according to the Engesser-KármánShanley's modified hypothesis.

Murawski, K. (2008b). Critical stress of squat cylindrical and squere shaped plywood made of birch compressed by ball-and-socket joints according to the Engesser-Karman-Shanley's modified hypothesis. Annals of Warsaw University of Life SciencesSGGW. Forestry and Wood Technology, 64.

Murawski, K. (2008c). Critical stress of squat cylindrical and square shaped plywood made of birch compressed by ball-and-socket joints according to the Březina's hypothesis, Annals of Warsaw University of Life Sciences - SGGW Forestry and Wood Technology No 64, 124-126.

Murawski, K. (2008d). Critical stress of squat cylindrical and square shaped plywood compressed by ball-andsocket joints according to the Tetmajer-Jasiński hypothesis. Annals of Warsaw University of Life Sciences - SGGW Forestry and Wood Technology No 64, 2008: 113-115.
Murawski, K. (2008e). Critical stress of squat cylindrical and square shaped plywood compressed by ball-and-socket joints according to the JohnsonOstenfeld hypothesis. Annals of Warsaw University of Life Sciences-SGGW. Forestry and Wood Technology, 64.

Murawski, K. (2011a). Teoria technicznej stateczności smukłych prętów sklejkowych. Oficyna Wydawnicza Politechniki Warszawskiej.

Murawski, K. (2011b). Theory of Technical Stability of Slender Plywood Rods. Publishing House of Warsaw University of Technology.

Murawski, K. (2011c). Modelowanie procesu pochłaniania energii w warstwowych zderzakach. Oficyna Wydawnicza Politechniki Warszawskiej.

Murawski, K. (2017). Modelling of the Energyabsorptive Process In Layered Bumpers. Lulu Press, Inc.

Murawski, K. (2018). Technical Stability of Very Slender Thin-walled Orthotropic Columns.

Murawski, K. (2020a). Lateral Buckling in Elastic-plastic States of Thin-walled Semi-slender Columns Made of Steel R35 According to Known Hypotheses.

Murawski, K. (2020b). Experimental Results of Lateral Buckling of Thin-walled Semi-slender Columns with Pinned Ends Made of Steel R35 in the Elastic-plastic States in Comparison to the Known Hypotheses.

Ostenfeld, A. (1898). Exzentrische und zentrische Knickfestigkeit. VDI-Z, 94, 1462-1470.

Papanastasiou, P., \& Durban, D. (1999). Bifurcation of elastoplastic pressure-sensitive hollow cylinders.

Pearson C. E. (1950). Bifurcation Criterion and Plastic Buckling of Plates and Columns. Jour. Aeronaut Sci., 17, 417.

Radhakrishnan, S. (1956). Plastic buckling of circular cylinders. Journal of the Aeronautical Sciences, 23(9), 892-894.

Shanley, F. R. (1947). Inelastic column theory. Journal of the aeronautical sciences, 14(5), 261-268.

Silvestre, N., Abambres, M., \& Camotim, D. (2018). Influence of the deformation mode nature on the $1 \mathrm{st}$ order post-yielding strength of thin-walled beams. Thin-Walled Structures, 128, 71-79.

Słowiński, K., \& Piekarczyk, M. (2017). 04.18: Determination of the plastic limit load for a cylindrical shell under general loading conditions using FEA. ce/papers, 1(2-3), 980-989.

Standard DIN 4114. (1953). Steel Construction; Stability Cases (Buckling, Tilting, Bulging), Design Principles, Guidelines. Publisher: German Institute for Standardisation (Deutsches Institut für Normung). 
Stowell, E. Z. (1948). A Unified theory of plastic buckling of columns and plates, NACA Tech. Note.

Seide, P., Weingarten, V. I., \& Morgan, E. J. (1960). The development of design criteria for elastic stability of thin shell structures (No. EM-10-26). TRW Space Technology Labs Los Angeles CA.

Tetmajer, L. (1886). Mittheilungen der Anstalt zur Prüfung von Baumaterialien am eidg. Polytechnikum in Zürich. 1.Heft: Methoden und Resultate der Prüfung natürlicher und künstlicher Bausteine, Zürich.
Vol'mir A. S., 1965. Stability of elastic systems. Foreign technology Division, Wright Patterson Air Force Base, Ohio.

Voyiadjis, G. Z., \& Woelke, P. (2008). Elasto-plastic and damage analysis of plates and shells. Springer Science \& Business Media.

Ylinen, A. (1956). A method of determining the buckling stress and the required cross-sectional area for centrally loaded straight columns in elastic and inelastic range. Mem Assoc Int Ponts Charpentes, $16,529-550$. 